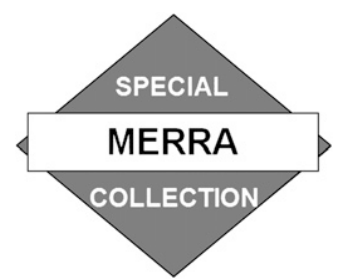

\title{
An Assessment of Precipitation Changes over Antarctica and the Southern Ocean since 1989 in Contemporary Global Reanalyses*
}

\author{
DAVID H. BROMWICH AND JULIEN P. NiCOLAS \\ Polar Meteorology Group, Byrd Polar Research Center, and Atmospheric Sciences Program, Department of Geography, \\ The Ohio State University, Columbus, Ohio \\ ANDREW J. MONAGHAN \\ Research Applications Laboratory, National Center for Atmospheric Research, Boulder, Colorado
}

(Manuscript received 16 September 2010, in final form 31 January 2011)

\begin{abstract}
This study evaluates the temporal variability of the Antarctic surface mass balance, approximated as precipitation minus evaporation $(P-E)$, and Southern Ocean precipitation in five global reanalyses during 1989-2009. The datasets consist of the NCEP/U.S. Department of Energy (DOE) Atmospheric Model Intercomparison Project 2 reanalysis (NCEP-2), the Japan Meteorological Agency (JMA) 25-year Reanalysis (JRA-25), ECMWF Interim Re-Analysis (ERA-Interim), NASA Modern Era Retrospective-Analysis for Research and Application (MERRA), and the Climate Forecast System Reanalysis (CFSR). Reanalyses are known to be prone to spurious trends and inhomogeneities caused by changes in the observing system, especially in the data-sparse high southern latitudes. The period of study has seen a dramatic increase in the amount of satellite observations used for data assimilation.

The large positive and statistically significant trends in mean Antarctic $P-E$ and mean Southern Ocean precipitation in NCEP-2, JRA-25, and MERRA are found to be largely spurious. The origin of these artifacts varies between reanalyses. Notably, a precipitation jump in MERRA in the late 1990s coincides with the start of the assimilation of radiances from the Advanced Microwave Sounding Unit (AMSU). ERA-Interim and CFSR do not exhibit any significant trends. However, the potential impact of the assimilation of rain-affected radiances in ERA-Interim and inhomogeneities in CFSR pressure fields over Antarctica cast some doubt on the reliability of these two datasets.

The authors conclude that ERA-Interim likely offers the most realistic depiction of precipitation changes in high southern latitudes during 1989-2009. The range of the trends in Antarctic $P-E$ among the reanalyses is equivalent to $1 \mathrm{~mm}$ of sea level over 21 years, which highlights the improvements still needed in reanalysis simulations to better assess the contribution of Antarctica to sea level rise. Finally, this work argues for continuing cautious use of reanalysis datasets for climate change assessment.
\end{abstract}

\section{Introduction}

Over the last decade, there has been increasing evidence of a positive contribution of the Antarctic Ice Sheet to global sea level rise (Allison et al. 2009). The corresponding ice mass loss is mainly driven by enhanced ice

* Byrd Polar Research Center Contribution Number 1406.

Corresponding author address: David H. Bromwich, Polar Meteorology Group, Byrd Polar Research Center, The Ohio State University, 1090 Carmack Road, Columbus, OH 43210.

E-mail: bromwich.1@osu.edu discharge into the ocean from West Antarctica and the Antarctic Peninsula (Rignot et al. 2008; Pritchard et al. 2009); see geographic names in Fig. 1. There is, however, considerable uncertainty as to how the ice sheet's surface mass balance (SMB) has been responding to recent climate change. This uncertainty is due in part to the high temporal variability of the SMB, which makes it difficult to detect potential climate change signals (Monaghan and Bromwich 2008). Previous studies have reported insignificant trends in the overall Antarctic SMB since the late 1950s (Monaghan et al. 2006b) as well as since the early 1980s (van de Berg et al. 2005; Monaghan et al. 2006a). With the equivalent of $6 \mathrm{~mm}$ global mean sea 


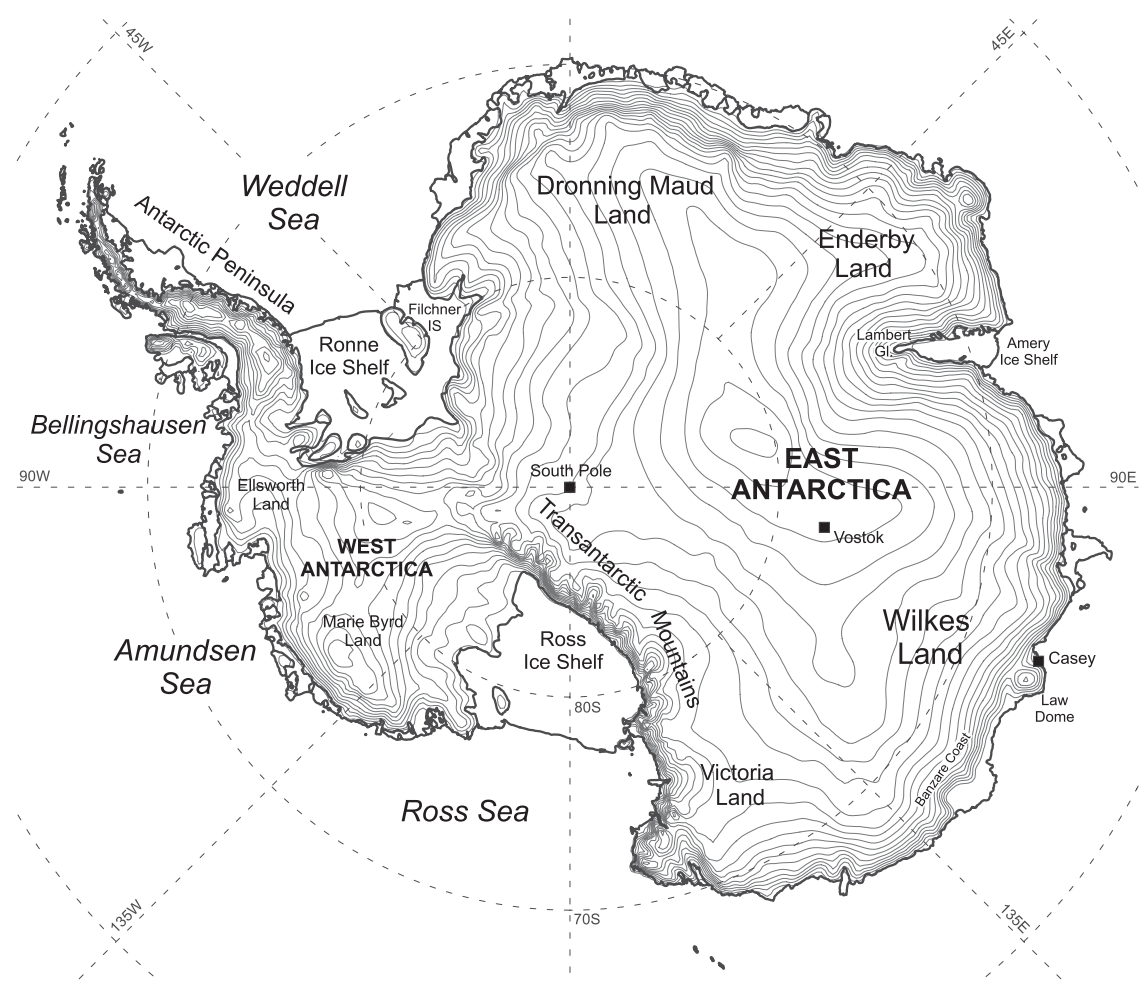

FIG. 1. Map of Antarctica showing elevation contours with 200-m intervals (topography from Liu et al. 2001).

level falling each year as snowfall on the ice sheet (Church et al. 2001), the evolution of the Antarctic SMB remains an important aspect of present and future sea level changes.

Owing to extremely low atmospheric moisture content over the continent, Antarctic snowfall-the main component of the SMB-largely results from moisture advection from the surrounding ocean areas (Tietäväinen and Vihma 2008; Sodemann and Stohl 2009). Thus, variations in Antarctic SMB are intimately linked to changes in Southern Ocean precipitation, both of which are examined in this paper. In addition, future climate simulations show that precipitation changes over the Antarctic are paired with those in the adjacent sector of the Southern Ocean (e.g., Christensen et al. 2007).

Global reanalyses potentially provide valuable resources for investigating climate change during recent decades. These datasets are produced with a numerical weather prediction model anchored with a variety of meteorological observations. Importantly, these observations do not include precipitation rates. Three new global reanalyses have been produced since 2008: the European Centre for Medium-Range Weather Forecasts "Interim" reanalysis (ERA-Interim) (Simmons et al. 2006; Uppala et al. 2008); the National Aeronautics and Space Administration Modern Era Retrospective-Analysis for Research and Applications (MERRA) (Bosilovich et al. 2006; Cullather and Bosilovich 2011); and the National Centers for Environmental Prediction (NCEP) Climate Forecast System Reanalysis (CFSR) (Saha et al. 2010). In addition, two previous reanalysis projects have been continued up to near real-time: the NCEP/Department of Energy Atmospheric Model Intercomparison Project 2 (AMIP-2) reanalysis (NCEP-2) (Kanamitsu et al. 2002); and the Japan Meteorological Agency (JMA) 25-year Reanalysis (JRA-25) (Onogi et al. 2007).

There are nevertheless some important caveats to using reanalyses for climate change assessment. While the use of a fixed assimilation system and forecasting model eliminates spurious shifts in the data caused by model upgrades (Bengtsson and Shukla 1988), the reanalyses remain sensitive to changes in the observing system (Bengtsson et al. 2004a,b). This sensitivity is exacerbated in high southern latitudes owing to limited observational constraints (Hines et al. 2000; Marshall 2002; Bromwich and Fogt 2004; Bromwich et al. 2007). For example, the introduction of satellite atmospheric sounding data in late 1978 produced a jump in the Antarctic SMB simulated by the 40-yr European Centre for Medium-Range Weather Forecasts Re-Analysis (ERA-40) (van de Berg et al. 2005; Bromwich et al. 2007). In mid-1987, JRA-25 precipitation exhibits a sudden drop over the Southern Ocean as a 
TABLE 1. Characteristics of the reanalyses used in this study, presented in their chronological order of release. (Note: CRIEPI is the acronym for Central Research Institute of Electric Power Industry.)

\begin{tabular}{|c|c|c|c|c|c|c|}
\hline Reanalysis & Organization & $\begin{array}{c}\text { Time } \\
\text { coverage }\end{array}$ & $\begin{array}{l}\text { Horizontal } \\
\text { resolution }\end{array}$ & $\begin{array}{c}\text { Vertical } \\
\text { levels }\end{array}$ & $\begin{array}{l}\text { Assimilation } \\
\text { system }\end{array}$ & $\begin{array}{c}\text { Satellite } \\
\text { data used }^{\text {a }}\end{array}$ \\
\hline NCEP-2 & NCEP/DOE & 1979-present & $\mathrm{T} 62, \sim 210 \mathrm{~km}$ & 28 & 3DVAR & Retrievals \\
\hline ERA-40 & ECMWF & 1957-Aug 2002 & $\mathrm{~T} 159, \sim 125 \mathrm{~km}$ & 60 & 3DVAR & Radiances \\
\hline JRA-25 & JMA/ CRIEPI & 1979-present & $\mathrm{T} 106, \sim 125 \mathrm{~km}$ & 40 & 3DVAR & Radiances + VarBC $^{b}$ \\
\hline ERA-Interim & ECMWF & 1989-present & $\mathrm{T} 255, \sim 80 \mathrm{~km}$ & 60 & 4DVAR & Radiances + VarBC \\
\hline MERRA & NASA GMAO & 1979-present & $1 / 2^{\circ} \times 2 / 3^{\circ}, \sim 55 \mathrm{~km}^{\mathrm{c}}$ & 72 & 3DVAR & Radiances + VarBC \\
\hline CFSR & NCEP & 1979-present & $\mathrm{T} 382, \sim 38 \mathrm{~km}$ & 64 & 3DVAR & Radiances + VarBC \\
\hline
\end{tabular}

${ }^{\text {a }}$ VarBC: Variational bias correction of satellite radiances.

b JRA-25 used VarBC with TOVS and static bias correction with ATOVS radiances (Onogi et al. 2007).

${ }^{\mathrm{c}}$ Resolution in latitude.

result of the assimilation of observations from the Special Sensor Microwave Imager (SSM/I) (Bosilovich et al. 2006). Furthermore, reanalyses may be contaminated by artificial trends in the data, such as caused by a temporal drift of satellite radiances (Dee and Uppala 2008, 2009).

The most recent reanalyses have benefited from advances in operational weather forecasting and guidance from previous reanalysis efforts (Bengtsson et al. 2007). A variational bias correction, allowing for an automatic and adaptive handling of biases in satellite radiances, has been implemented in ERA-Interim, MERRA, and CFSR. Improved analysis of moisture has been made possible through a four-dimensional variational (4DVAR) assimilation system in ERA-Interim (Andersson et al. 2007; Simmons et al. 2010) or a nudging technique in MERRA (Cullather and Bosilovich 2011). Observation error statistics from previous reanalysis experiments have served to produce higher-quality observation datasets (Haimberger 2007). Finally, increased computational power has allowed for higher horizontal and vertical model resolution, a critical aspect for the modeling of Antarctic SMB because of the importance of orographic precipitation on the ice sheet's steep coastal slopes.

The onset of the modern satellite era in 1979 represented a major transition toward a mostly satellite-based observing system (Bengtsson et al. 2004a). This system has also profoundly evolved in the recent decades. In particular, a number of polar-orbiting satellites have been launched in the late 1990s and early 2000s, providing enhanced data coverage of the high latitudes on daily and subdaily time scales. The operation of these new satellites has brought about a dramatic increase in the volume of satellite observations available for data assimilation (Dee et al. 2009; Saha et al. 2010) - to the point that some parallel can be drawn with the late 1970s "shock" in the global observing system (Bromwich and Fogt 2004). It is noteworthy that these transformations have been largely confined to areas outside Antarctica because the difficult detection of clouds and uncertainties in surface emissivity still largely preclude the assimilation of satellite radiances over ice sheets (Bouchard et al. 2010; Guedj et al. 2010). Over Antarctica, the reanalyses still rely primarily on a sparse network of terrestrial observations (Andersson 2007).

The purpose of our study is to assess the realism of the changes in the hydrological cycle in high southern latitudes as depicted by the global reanalyses, especially how some of these datasets have responded to the massive input of satellite observations in the late 1990s/early 2000s. The paper is organized as follows. In section 2, the data and methodology are presented. In Section 3, the mean annual Antarctic net precipitation $(P-E)$ from the reanalyses during 1989-2009 is examined and evaluated against long-term observations. Sections 4 and 5 investigate the temporal variability and trends in Antarctic $P-E$ and Southern Ocean precipitation, respectively. Section 6 describes the changes in the atmospheric circulation in high southern latitudes in an effort to account for some of the trends in Antarctic $P-E$ observed in the reanalyses. A summary and some implications of our results are given in Section 7.

\section{Data and methodology}

\section{a. Reanalysis datasets}

Six global reanalysis datasets are examined: NCEP-2, ERA-40, JRA-25, ERA-Interim, MERRA, and CFSR. The use of ERA-40 is more secondary, as it does not provide data beyond August 2002. The main characteristics of the reanalyses are summarized in Table 1.

NCEP-2 and ERA-40 (Uppala et al. 2005) have been widely used in the literature and will not be redescribed here. Worth noting, however, is that NCEP-2 has the coarsest horizontal and vertical resolutions among the six reanalyses and makes limited use of satellite observations. In particular, it does not ingest any SSM/I observations (Kanamitsu et al. 2002).

JRA-25 is based on the JMA operational forecasting model and assimilation system as of April 2004. As such, it 
is the first reanalysis to take advantage of some observations from the constellation of polar-orbiting satellites launched in the late 1990s-early 2000s, especially as part of NASA's Earth Observing System (EOS) Program [e.g., Quick Scatterometer (QuikSCAT), Terra, and Aqua satellites]. Evaluation of JRA-25 precipitation showed higher correlation with global precipitation analyses than NCEP-2 and ERA-40 (Onogi et al. 2007; Bosilovich et al. 2008).

ERA-Interim starts in 1989 and, to date, is the only reanalysis using a 4DVAR assimilation system (Dee and Uppala 2009). Biases in satellite radiances are corrected via a variational bias correction scheme (Dee and Uppala 2008, 2009). A similar technique is also used to handle biases in surface pressure observations (Vasiljevic et al. 2006). Thanks to improved model physics and moisture analysis, ERA-Interim has eliminated some of the problems with the representation of the hydrological cycle in ERA-40 (Andersson et al. 2005; Uppala et al. 2008). The ERA-Interim data obtained from the ECMWF online data server are downgraded from the original model grid to a regular $1.5^{\circ} \times 1.5^{\circ}$ latitude-longitude resolution.

MERRA is the second reanalysis produced by NASA's Global Modeling and Assimilation Office (GMAO). It implements a 3DVAR assimilation system, the Gridpoint Statistical Interpolation (GSI) scheme (Kleist et al. 2009); a variational bias correction of satellite radiances; and the Incremental Analysis Updates (IAU), a nudging technique allowing for a smooth transition from the model states toward the observed state (Rienecker et al. 2008; Cullather and Bosilovich 2011). Test evaluations of MERRA precipitation for two months in 2004 revealed performance equal to or greater than other reanalyses (Bosilovich et al. 2008).

CFSR was completed in January 2010 with data currently spanning 1979-2009. It brings major improvements to NCEP-2, including higher horizontal and vertical resolutions (highest among the global reanalyses used in this study) and intensive use of satellite observations (assimilating satellite radiances instead of satellite retrievals). Similar to MERRA, atmospheric observations are assimilated via the 3DVAR GSI system. Unique among current global reanalyses, CFSR uses a coupled atmosphereocean-sea ice-land model for its short-term forecasts.

The precipitation $(P)$ and surface evaporation/sublimation $(E)$ data are taken from the reanalyses forecast fields. The $E$ is not available in NCEP-2 and JRA-25 and is calculated (over Antarctica) from the latent heat fluxes at the surface using a constant latent heat of sublimation of $2.838 \times$ $10^{6} \mathrm{~J} \mathrm{~kg}^{-1}$, after Rogers and Yau (1989).

\section{b. Antarctic SMB and other methodological aspects}

Over Antarctica, precipitation minus surface evaporation/ sublimation $(P-E)$ is used as an approximation of the ice sheet's SMB. The $P-E$ neglects some ablation processes such as melt/runoff, horizontal snow transport, and blowing-snow sublimation. Melt/runoff is mostly confined to the coastal ice shelves. On the continent, meltwater generally refreezes within the snowpack, thereby contributing negligibly to the overall SMB (Liston and Winther 2005). The two wind-induced processes (not represented in the reanalysis models) are most consequential in the escarpment zone, where the katabatic flow is strongest, and can lead locally to a complete removal of the annual snowfall (Frezzotti et al. 2004; van den Broeke et al. 2004; Frezzotti et al. 2007; Genthon et al. 2007; Lenaerts et al. 2010; Scarchilli et al. 2010). Averaged over the entire ice sheet, the wind divergence/convergence term becomes a second-order contributor to the SMB (Déry and Yau 2002; van den Broeke et al. 2006b). On the other hand, the average blowing-snow sublimation is of the same order as surface sublimation, accounting for $10 \%-20 \%$ of precipitation (Bintanja 1998; Déry and Yau 2002; van den Broeke et al. 2006b). With regards to the positive contributions to the SMB, none of the reanalysis models includes a representation of clear-sky precipitation, a potentially important, yet uncertain, component on the plateau (Bromwich 1988; Fujita and Abe 2006).

As will be demonstrated hereafter, the differences in the magnitude and temporal variability of $P$ and $E$ among the reanalyses are of first order. Thus, we estimate that a refined calculation of the SMB is not justified at this point and may further complicate the understanding of discrepancies between reanalyses.

The contours of the grounded ice sheet and the floating ice shelves are taken from Vaughan et al. (1999, hereafter V99), available at $1^{\circ} \times 1^{\circ}$ latitude-longitude resolution. To compute spatially averaged SMB estimates for the entire ice sheet and allow for uniform comparison between the datasets, the reanalysis data are bilinearly interpolated to a $1^{\circ} \times 1^{\circ}$ grid. Unless otherwise mentioned, the reanalysis data are plotted spatially with the same resolution as that with which they were obtained.

Temporally, our main focus is 1989-2009, the period of overlap between the reanalyses. For completeness, the time series are generally shown for 1979-2009. Twentyone years is admittedly too short a period to capture longterm trends in the Antarctic SMB. Here, the use of linear temporal trends aims primarily to detect problems in the reanalyses.

\section{c. Observation-based datasets}

Over Antarctica, the reanalysis $P-E$ is compared with the observation-based accumulation map from Arthern et al. (2006, hereafter referred to as A06), available at a resolution of $100 \mathrm{~km} \times 100 \mathrm{~km}$. This dataset is based on the same compilation of in situ measurements as the 
maps from V99, but employs an improved background field to guide the interpolation: satellite passive microwave and thermal infrared (TIR) observations for A06 versus TIR only for V99. The map from A06 incorporates glaciological observations collected since the 1950s but heterogeneously distributed in time. This dataset can thus be considered as a depiction of the long-term Antarctic SMB, assuming that no significant change in the long-term accumulation has occurred in Antarctica during the secondhalf of the twentieth century. This assumption, which is also required to compare A06 with the reanalysis data, is supported by the results from Monaghan et al. (2006b) and Monaghan and Bromwich (2008). To compare with the reanalyses, the map from A06 is interpolated to a $1^{\circ} \times$ $1^{\circ}$ grid.

Importantly, the accuracy of the V99 and A06 maps in some areas has been questioned because of the use of unreliable accumulation measurements (Frezzotti et al. 2004; Magand et al. 2007; Genthon et al. 2009). Additionally, the passive microwave background used by A06 was shown to be unreliable in coastal areas affected by melt/refreeze during summer (Magand et al. 2008). Nonetheless, A06 showed that their dataset alleviates some of the biases present in V99, producing especially lower accumulation values on the East Antarctic plateau.

Over the Southern Ocean, we use two satellite-gauge precipitation analysis datasets to evaluate the reanalysis precipitation: the version 2 Global Precipitation Climatology Project (GPCP) merged precipitation data (Adler et al. 2003) and the Climate Prediction Center Merged Analysis of Precipitation (CMAP) (Xie and Arkin 1997). These datasets provide gridded monthly precipitation data at $2.5^{\circ} \times 2.5^{\circ}$ resolution. CMAP has missing data poleward of $60^{\circ} \mathrm{S}$. GPCP data provide a global coverage but its precipitation estimates over ice-covered areas are deemed unreliable (Serreze et al. 2005).

Monthly observations of mean sea level pressure and $500-\mathrm{hPa}$ geopotential height from manned Antarctic stations were obtained from the British Antarctic Survey READER database (http://www.antarctica.ac.uk/ met/READER/).

\section{1989-2009 mean annual Antarctic $P-E$}

An accurate representation of the long-term Antarctic $P-E$ is the first challenge faced by the reanalyses whose model physics is generally tuned for the mid and lowlatitude climate, not for the extreme conditions found in Antarctica. Monaghan et al. (2006a) and van de Berg et al. (2006) summarized several Antarctic SMB estimates from recent studies, showing a significant scatter among the results (84-180 mm yr ${ }^{-1}$ on average for the grounded ice sheet). The recently produced reanalyses provide new simulations to compare with previous estimates.

\section{a. Spatial distribution of Antarctic mean annual $P-E$}

The spatial distributions of mean annual $P-E$ from the five reanalyses during 1989-2009 are presented in Fig. 2, along with the accumulation map from A06. NCEP-2 notwithstanding, the reanalyses correctly reproduce the known contrast between the high-accumulation coast and the dry interior. NCEP-2, on the other hand, shows small net precipitation rates over most of coastal East Antarctica. As already noted by Monaghan et al. (2006a), these low values are due to unrealistically high surface sublimation fluxes (see also section 3c), linked to overestimated latent heat fluxes in stable boundary layer conditions (Hines et al. 1999). In coastal areas, ERAInterim, MERRA, and CFSR capture the leeward/ windward precipitation gradient, for example, across Law Dome $\left(110^{\circ} \mathrm{E}\right)$ (van Ommen et al. 2004).

Over the East Antarctic interior, the differences between the reanalyses are enhanced by the nonlinear color scale. Over most of the plateau, JRA-25 exhibits $P-E$ values $>50 \mathrm{~mm} \mathrm{yr}^{-1}$, with maxima $>100 \mathrm{~mm} \mathrm{yr}^{-1}$, whereas ERA-Interim exhibits values $<10 \mathrm{~mm} \mathrm{yr}^{-1}$. Intermediate accumulation rates are found in MERRA and CFSR. The locations of negative $P-E$ in CFSR agree well with observed blue-ice areas (Winther et al. 2001). Because these ablation areas result from wind processes not included in the reanalysis, such agreement would rather suggest insufficient $P$ or excessive $E$ locally in CFSR.

In West Antarctica, relatively good agreement is found between the datasets. The model resolution (Table 1) greatly affects the precipitation gradient in coastal areas, with enhanced orographic precipitation produced in the higher-resolution models, for example, in Marie Byrd Land.

The map from A06 (Fig. 2f) shows lower coastal accumulation rates than the reanalyses, a result of ablation processes not accounted for by $P-E$ and of excessively low values in A06 in coastal areas (Magand et al. 2007, 2008).

\section{b. Comparison of reanalysis $P-E$ with observations}

Figure 3 presents the ratio between the distribution of the reanalysis mean annual $P-E$ and the accumulation map from A06. Here $P-E$ better approximates the "true" SMB on the plateau (as compared to the coast) because of weaker katabatic winds and thus lower contribution of wind-driven ablation processes.

The large positive biases $\left(>200 \mathrm{~mm} \mathrm{yr}^{-1}\right)$ found in all five reanalyses over Marie Byrd Land, West Antarctica, result from strongly underestimated accumulation rates 

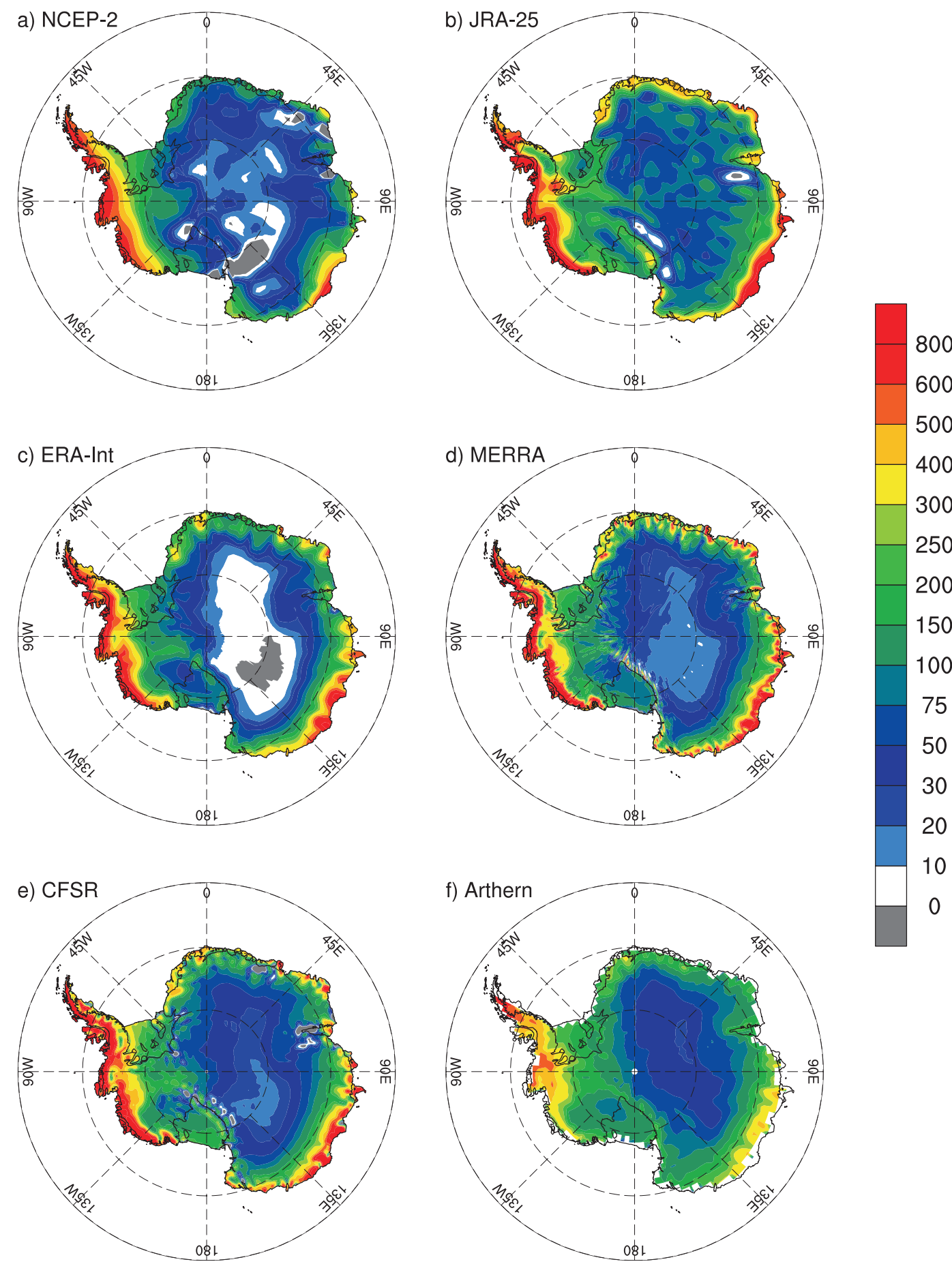

FIG. 2. 1989-2009 mean annual net precipitation $(P-E)\left(\mathrm{mm} \mathrm{yr}^{-1}\right)$ from (a) NCEP-2, (b) JRA-25, (c) ERA-Interim, (d) MERRA, and (e) CFSR. (f) Accumulation map from Arthern et al. (2006).

obtained from stratigraphic observations used in A06 (van de Berg et al. 2006; van den Broeke et al. 2006a). Figure 3a confirms the excessively low $P-E$ values in NCEP-2 seen in Fig. 2a. Over a large fraction of the East Antarctic plateau, especially its highest-elevated part, the overestimation of accumulation in JRA-25 exceeds $60 \%$ compared to A06. Onogi et al. (2007) indicate that such excessive snowfall may be related to the spectral truncation of model variables in regions with extremely low saturated water pressure vapor. 

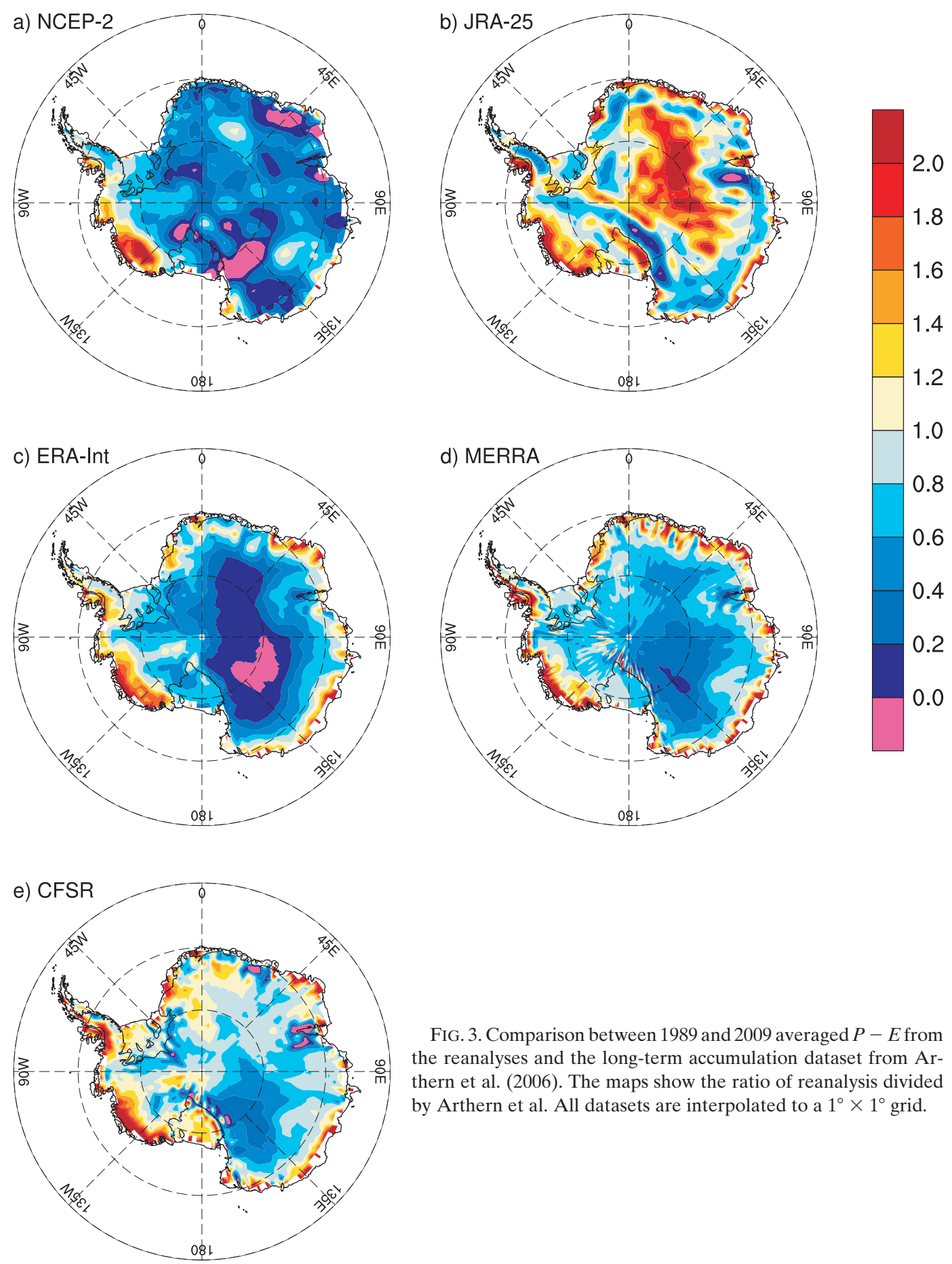

FIG. 3. Comparison between 1989 and 2009 averaged $P-E$ from the reanalyses and the long-term accumulation dataset from Arthern et al. (2006). The maps show the ratio of reanalysis divided by Arthern et al. All datasets are interpolated to a $1^{\circ} \times 1^{\circ}$ grid.

On the East Antarctic plateau, mainly above $2500 \mathrm{~m}$ MSL, $P-E$ in ERA-Interim represents less than $20 \%$ of the accumulation values from A06, with a large area of net ablation. Magand et al. (2007) applied a strict qualitycontrol filtering to the observations used by A06 in the $90^{\circ} \mathrm{E}-180^{\circ}$ quadrant. They find long-term accumulation rates of $>40 \mathrm{~mm} \mathrm{yr}^{-1}$ both in the $3000-3500-\mathrm{m}$ and 3500-4000-m elevation ranges, which confirms the dry bias in ERA-Interim. Other recent accumulation measurements in the hinterland of Dronning Maud Land generally produce values $>20 \mathrm{~mm} \mathrm{yr}^{-1}$ (e.g., Kameda et al. 2008; Anschütz et al. 2009). It is noteworthy that the dry bias is significantly reduced when ERA-Interim $P-E$ is estimated from the atmospheric moisture flux budget 
TABLE 2. 1989-2009 average values for $P, E$, and $P-E\left(\mathrm{~mm} \mathrm{yr}^{-1}\right)$ from the reanalyses, spatially averaged over the grounded ice sheet $\left(12.35 \times 10^{6} \mathrm{~km}^{2}\right)$ and over the total ice sheet $\left(13.82 \times 10^{6} \mathrm{~km}^{2}\right)$, which includes the ice shelves. For ERA-40 and ERA-Interim, the values are also shown for their period of overlap (1989-2001). The uncertainties correspond to the standard error of the mean multiplied by 1.96 to encompass the $95 \%$ confidence interval (assuming values normally distributed).

\begin{tabular}{|c|c|c|c|c|c|c|}
\hline \multirow[b]{2}{*}{ Reanalysis } & \multicolumn{3}{|c|}{ Grounded ice sheet } & \multicolumn{3}{|c|}{ Total ice sheet } \\
\hline & $P$ & E & $P-E$ & $P$ & $E$ & $P-E$ \\
\hline \multicolumn{7}{|c|}{ 1989-2009 } \\
\hline NCEP-2 & $172 \pm 5$ & $93 \pm 3$ & $79 \pm 3$ & $185 \pm 5$ & $96 \pm 3$ & $89 \pm 4$ \\
\hline JRA-25 & $203 \pm 5$ & $49 \pm 1$ & $154 \pm 5$ & $223 \pm 5$ & $51 \pm 1$ & $172 \pm 5$ \\
\hline ERA-Interim & $148 \pm 3$ & $19 \pm 1$ & $130 \pm 3$ & $164 \pm 3$ & $22 \pm 1$ & $142 \pm 3$ \\
\hline MERRA & $169 \pm 5$ & $12 \pm 1$ & $157 \pm 5$ & $183 \pm 5$ & $15 \pm 1$ & $168 \pm 6$ \\
\hline CFSR & $201 \pm 4$ & $46 \pm 1$ & $155 \pm 4$ & $224 \pm 4$ & $53 \pm 1$ & $171 \pm 4$ \\
\hline \multicolumn{7}{|c|}{ 1989-2001 } \\
\hline ERA-40 & $145 \pm 4$ & $26 \pm 1$ & $119 \pm 4$ & $162 \pm 5$ & $30 \pm 1$ & $132 \pm 4$ \\
\hline ERA-Interim & $147 \pm 4$ & $18 \pm 1$ & $129 \pm 4$ & $163 \pm 4$ & $21 \pm 1$ & $141 \pm 4$ \\
\hline
\end{tabular}

method (e.g., Bromwich and Wang 2008) rather than from the reanalysis forecast fields (L. Bengtsson, personal communication 2010).

MERRA and CFSR show better agreement with A06 overall. Because $P-E$ does not account for wind-induced ablation, one would expect ratios $>1$ not only in the immediate coastal band (as seen in Figs. 3d and 3e) but also farther inland. Therefore, ratios within 0.6-1.0 rather suggest underestimated precipitation in MERRA and CFSR.

c. Total Antarctic $P-E$

The 1989-2009 mean annual values for $P, E$, and $P-E$ spatially averaged over the Antarctic Ice Sheet (grounded and with ice shelves) are reported in Table 2. Because of sublimation fluxes representing roughly $50 \%$ of the annual precipitation amount, NCEP-2 exhibits $P-E$ values substantially lower than the other datasets. JRA-25, MERRA, and CFSR show close $P-E$ values, within 154$157 \mathrm{~mm} \mathrm{yr}^{-1}$ averaged over the grounded ice sheet, although the similarity between JRA-25 and CFSR masks contrasting spatial distributions. These estimates compare well with $157 \pm 9 \mathrm{~mm} \mathrm{yr}^{-1}$ obtained by Monaghan et al. (2006a) for 1985-2001 with a regional climate model forced at the boundaries by NCEP-2. The observationbased dataset from A06 yields a somewhat lower value $\left(143 \pm 4 \mathrm{~mm} \mathrm{yr}^{-1}\right)$ as a result of lower coastal accumulation. Close to the $155-160 \mathrm{~mm} \mathrm{yr}^{-1}$ range are the results from van de Berg et al. (2006), $166 \mathrm{~mm} \mathrm{yr}^{-1}$ for 1980 2002, based on a regional climate model simulation forced by ERA-40, and from Krinner et al. (2007), $151 \mathrm{~mm} \mathrm{yr}^{-1}$ for 1980-99, based on a global coupled ocean-atmosphere model simulation. Note that all $P-E$ or snow accumulation estimates quoted in this paragraph are for the grounded ice sheet. With the lowest precipitation amount among the five reanalyses, ERA-Interim has $P-E$ values markedly smaller than the other reanalyses (except NCEP-2). Nevertheless, comparison between ERAInterim and ERA-40 over their period of overlap (19892001) reveals that ERA-Interim reduces the dry bias in ERA-40 because of smaller surface sublimation fluxes.

\section{Temporal variability and trends in Antarctic $\boldsymbol{P}-\boldsymbol{E}$}

The mean annual values and spatial distributions of the Antarctic $P-E$ described above largely depend upon the reanalysis model physics and configuration. The time series and trends in Antarctic $P-E$, examined in this section, reflect not only actual changes in the Antarctic climate but also the potential impact of the evolving observing system.

\section{a. Antarctic $P-E$ time series}

The time series of annual $P, E$, and $P-E$ spatially averaged over the grounded Antarctic Ice Sheet are shown in Fig. 4 and presented as anomalies from their respective temporal means during 1989-2001 (overlapping period).

Despite some common interannual variability, marked differences are seen across the datasets. NCEP-2 displays a pronounced upward trend in precipitation throughout the 31-yr period, which is not seen elsewhere (Fig. 4a). The reasons for such evolution are still unclear. MERRA departs markedly from the other reanalyses in 1999 and, during 1999-2009, exhibits precipitation on average $15 \mathrm{~mm}$ $(\sim 10 \%)$ greater than during $1979-98$. As indicated by Cullather and Bosilovich (2011), the upward shift in MERRA in the late 1990s is related to the assimilation of radiances from the Advanced Microwave Sounding Unit (AMSU). This instrument, which is part of the Advanced Television and Infrared Observation Satellite (TIROS) Operational Vertical Sounder (TOVS) (ATOVS) instrument suite, started being flown on the polar-orbiting NOAA satellites in May 1998. The impact of AMSU data in MERRA is further demonstrated in sections 5 and 6 .

From 2006 onward, a widening gap can be seen between ERA-Interim-CFSR and the three other reanalyses. It is not certain whether this must be attributed to changes in the assimilated observations. It is noteworthy that, in 2006, ERA-Interim and CFSR start assimilating Global Positioning System radio-occultation data from the Constellation Observing System for Meteorology Ionosphere and Climate (COSMIC) mission (Poli et al. 2010; Saha et al. 2010). These observations, which can be assimilated without bias correction, can be used over 

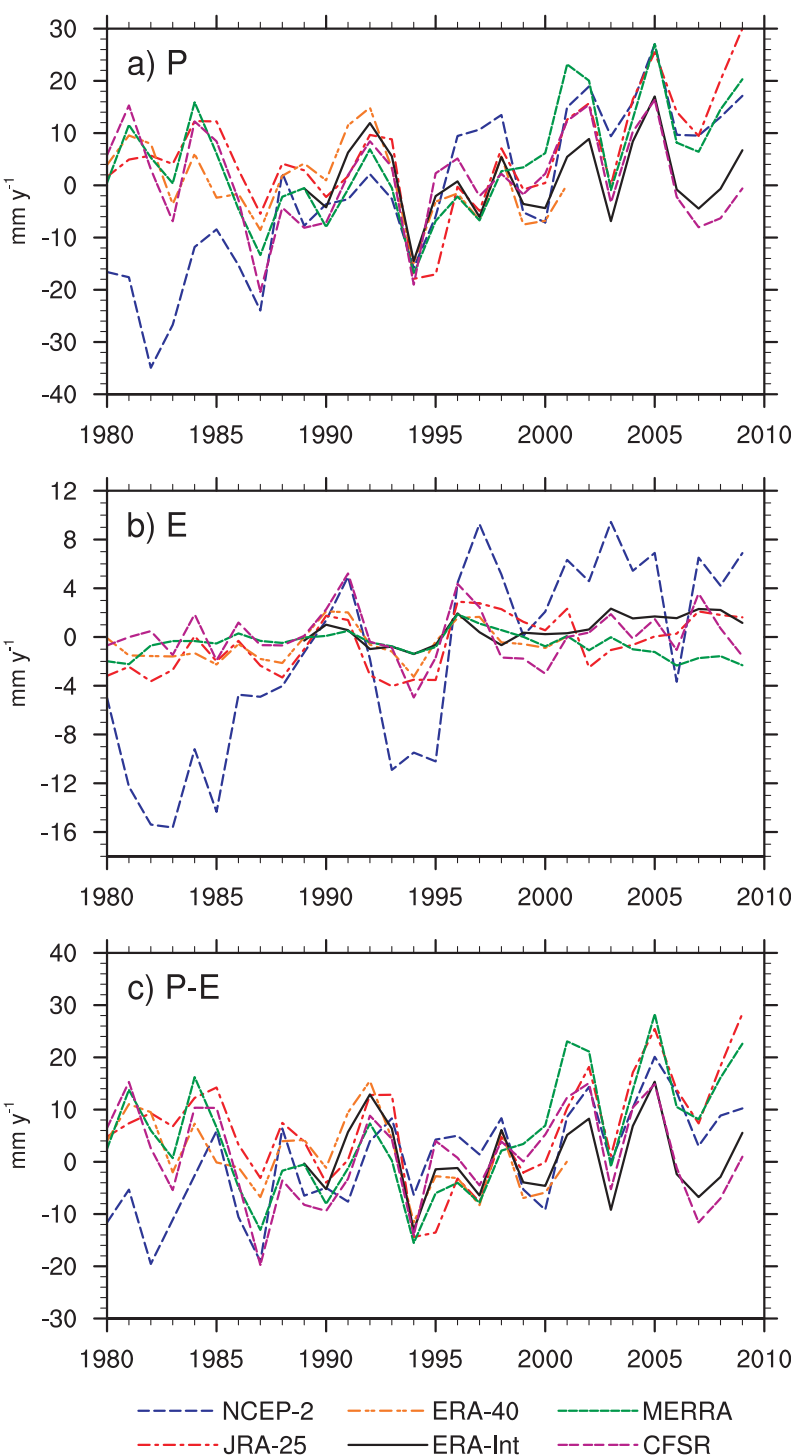

FIG. 4. Temporal series of annual (a) precipitation $P$, (b) evaporation/sublimation $E$, and (c) net precipitation $P-E$, in $\mathrm{mm} \mathrm{yr}^{-1}$ spatially averaged over the grounded Antarctic Ice Sheet from the six reanalyses. The series are presented as anomalies with respect to their respective 1989-2001 means.

Antarctica and have been shown to have a positive impact on the quality of analyses and forecasts in the Antarctic (Cucurull et al. 2006; Healy 2007).

The interannual variations in $E$ in NCEP-2 greatly exceed those in the other datasets (Fig. 4b). These variations are commensurate with the total sublimation fluxes in NCEP-2, shown to be unrealistically high (Table 2). With the exception of NCEP-2, the variations of $P-E$ largely mimic those of $P$. Therefore, the description of Fig. 4a can, to a large extent, be applied to Fig. 4c.
TABLE 3. Trends in Antarctic annual $P-E\left(\mathrm{~mm} \mathrm{yr}^{-1}\right.$ decade $\left.^{-1}\right)$ from the global reanalyses calculated for the 1979-2009 and 19892009 periods. The $P-E$ time series are for the grounded ice sheet. For 1979-2009, a linear trend is shown for a composite dataset (ECMWF) based on ERA-40 for 1979-88 and ERA-Interim for 1989-2009 (see text for the method). The uncertainties correspond to the standard error of the linear regression. Italic (bold) font indicates trends that are statistically different from zero at the $90 \%$ (99\%) confidence level.

\begin{tabular}{lcr}
\hline \hline Reanalysis & $1979-2009$ & $1989-2009$ \\
\hline NCEP-2 & $\mathbf{7 . 1} \pm \mathbf{1 . 5}$ & $\mathbf{7 . 8} \pm \mathbf{2 . 4}$ \\
JRA-25 & $4.0 \pm 2.0$ & $\mathbf{1 1 . 6} \pm \mathbf{3 . 5}$ \\
ERA-Interim & - & $0.5 \pm 2.7$ \\
MERRA & $5.5 \pm 2.0$ & $\mathbf{1 3 . 3} \pm \mathbf{3 . 1}$ \\
CFSR & $0.4 \pm 1.8$ & $2.6 \pm 3.1$ \\
ECMWF & $2.0 \pm 1.6$ & - \\
\hline
\end{tabular}

\section{b. Trends in total Antarctic $P-E$}

Table 3 presents the linear trends associated with the $P-E$ time series shown in Fig. 4c for the 1979-2009 and 1989-2009 periods, respectively. The statistical significance of the trends is estimated from the $p$ value of a two-tailed Student's $t$ test. For 1979-2009, an ECMWF composite is also included, based on ERA-40 for 1979-88 and on ERA-Interim for 1989-2009. ERA-40 values were adjusted upward by $5.50 \mathrm{~mm} \mathrm{yr}^{-1}$ based on the difference in mean annual $P-E$ between the two datasets during 1989-91.

For each of the three periods, the trends in $P-E$ in CFSR, ERA-Interim, and the ECMWF composite are not significantly different from zero $(p>0.1)$. For the whole 31-yr period, NCEP-2 shows the largest positive trend, significant at the $99 \%$ confidence level (CL), that is, $p<0.01$, and a very similar value for the 1989-2009 period. The trends in JRA-25 and MERRA are larger for the second, shorter period, following an overall decrease in $P-E$ during the 1980s. For both datasets, the trends are significant at the $90 \%$ CL for 1979-2009 and at the 99\% CL for 1989-2009. It is notable that, regardless of their statistical significance, all trends in Table 3 are positive.

\section{c. Spatial distribution of $P-E$ trends}

The temporal trends in average Antarctic $P-E$ mask important regional differences, with again contrasting pictures among the reanalyses (Fig. 5). Validating these trends against "ground-truth" observations is challenging. Only a few ice core accumulation records extend through the 2000 decade. Other in situ observations (e.g., stake farms) only provide a partial coverage of the 1989-2009 period.

ERA-Interim displays overall smaller and less significant trends than the other reanalyses. NCEP-2, JRA-25, and MERRA reveal large areas with highly significant upward trends in Dronning Maud Land (DML), albeit with rather dissimilar patterns. The analysis of shallow cores from 

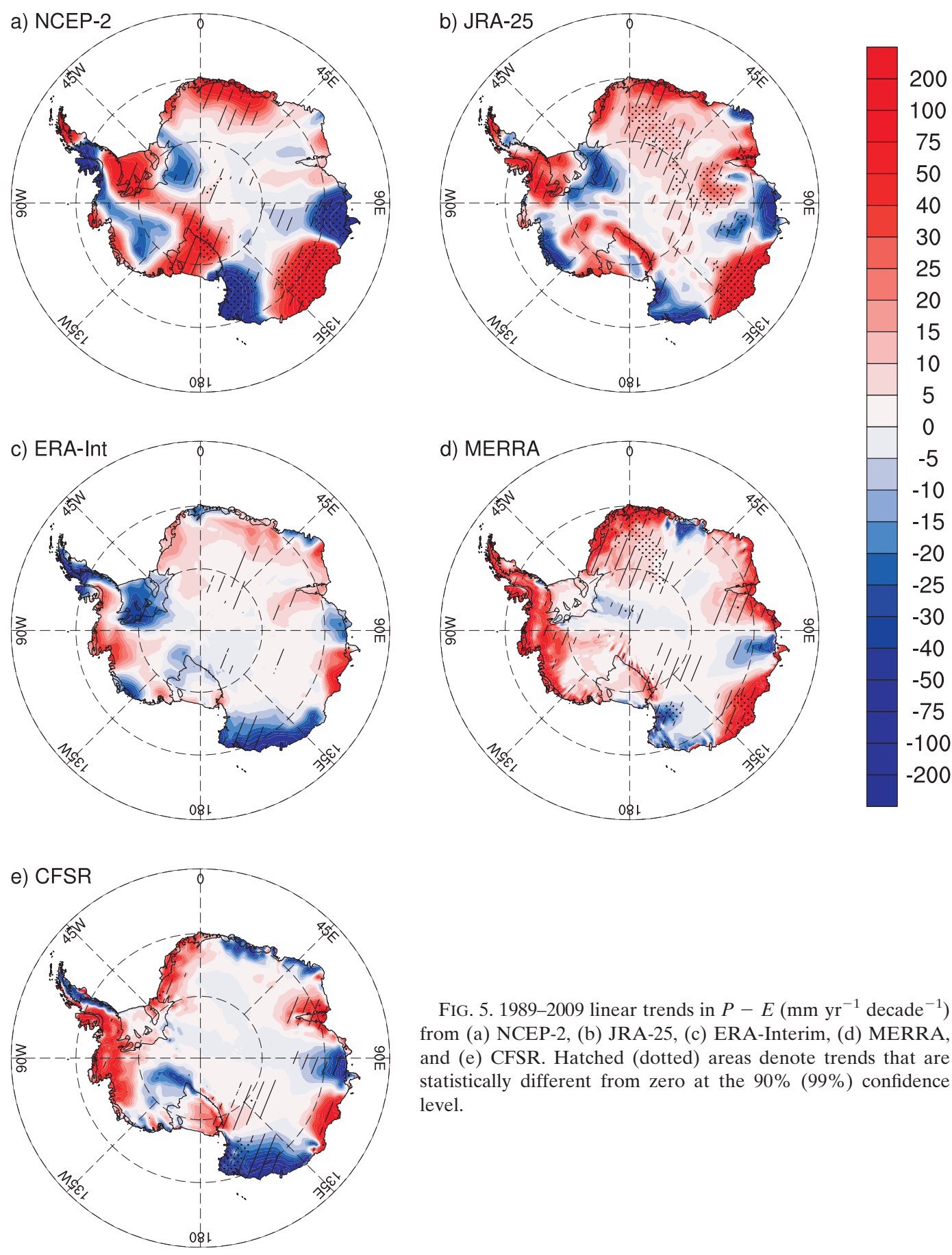

FIG. 5. 1989-2009 linear trends in $P-E\left(\mathrm{~mm} \mathrm{yr}^{-1}\right.$ decade $\left.^{-1}\right)$ from (a) NCEP-2, (b) JRA-25, (c) ERA-Interim, (d) MERRA, and (e) CFSR. Hatched (dotted) areas denote trends that are statistically different from zero at the $90 \%$ (99\%) confidence level.

coastal DML $\left(7^{\circ}-9^{\circ} \mathrm{W}\right)$ by Fernandoy et al. (2010) rather suggests decreasing accumulation through 1989-2007. A similar analysis done farther east $\left(\sim 12^{\circ} \mathrm{E}\right)$ by Anschütz et al. (2007) does not suggest any significant trend through 1989-2004.

Some similarity is found in the five maps in the $70^{\circ}-$ $170^{\circ} \mathrm{E}$ sector, with upward trends over Lambert Glacier and central Wilkes Land and downward trends over western Wilkes Land and Victoria Land. This alternation of patterns of opposite signs is suggestive of changes in the atmospheric circulation and the associated moisture advection toward/off the coast (see section 6). The magnitude and spatial extent of the patterns differ substantially among the reanalyses. NCEP-2 and JRA-25 exhibit trends 


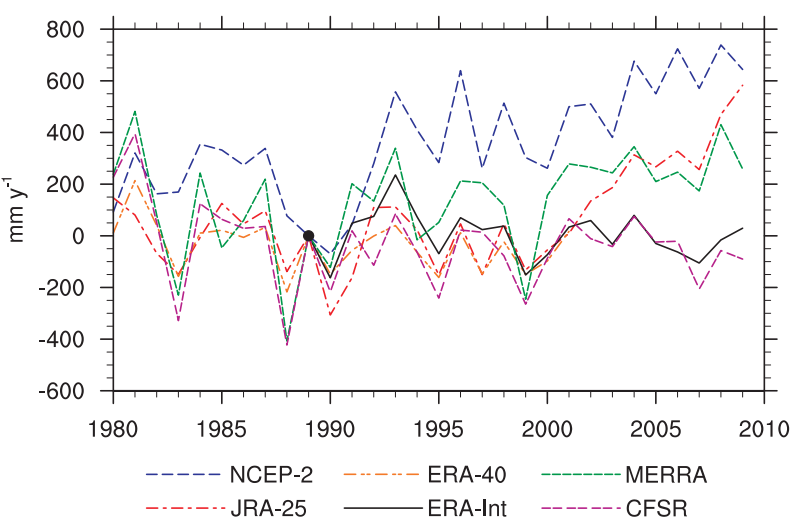

FIG. 6. Time series of $P-E\left(\mathrm{~mm} \mathrm{yr}^{-1}\right)$ over Banzare Coast, East Antarctica (see Fig. 1), from the six reanalysis datasets. The series are presented as anomalies with respect to their respective values in 1989.

in excess of $200 \mathrm{~mm} \mathrm{yr}^{-1}$ over extensive areas of central Wilkes Land, with local maxima of $390 \mathrm{~mm} \mathrm{yr}^{-1}$ decade $^{-1}$ and $290 \mathrm{~mm} \mathrm{yr}^{-1}$ decade $^{-1}$. Such large values cast doubts on the realism of the two reanalysis estimates in this sector. This is in contrast with zero or negative trends in ERA-Interim. All datasets except ERA-Interim have statistically significant (CL > 90\%) upward trends over Law Dome, whereas ice-core measurements indicate decreasing accumulation during 1989-2004 (van Ommen and Morgan 2010).

Over West Antarctica, the trends in $P-E$ are generally not statistically significant. The upward trends over Ellsworth Land in ERA-Interim, MERRA, and CFSR agree well with the marked increase in accumulation found at the nearby Gomez ice-core site from the 1970s through 2006 (Thomas et al. 2008). The patterns of large negative trends in $P-E$ over Victoria Land-a common feature among the five reanalyses - are consistent with increasing sea ice cover in the neighboring Ross Sea (Stammerjohn et al. 2008; Turner et al. 2009), both resulting from enhanced off-continent winds.

The pronounced trend differences in central Wilkes Land are further examined in Fig. 6, which shows the time series of annual $P-E$ over Banzare Coast $\left(128^{\circ} \mathrm{E}\right.$, see Fig. 1). The extreme positive trend in NCEP-2 during 19892009 largely results from an $\sim 400 \mathrm{~mm} \mathrm{yr}^{-1}$ increase in $P$ $E$ between 1989-91 and 1992-99 and a marked upward trend after 2000. While JRA-25 shows good agreement with ERA-Interim and CFSR throughout the 1990s, it exhibits a steady increase in $P-E$ after 2000, in sharp contrast with the two other reanalyses. This evolution results in an additional $600 \mathrm{~mm} \mathrm{yr}^{-1}$ in annual $P-E$ in 2009, as compared to 2000. As shown in section 6, the unrealistic trends in NCEP-2 and JRA-25 are likely related to spurious changes in the atmospheric circulation in this sector.

\section{Precipitation changes over the Southern Ocean}

In this section, we extend our analysis spatially to precipitation changes over the Southern Ocean. These changes are also put in a broader context by considering global and Southern Hemisphere precipitation. Importantly, the temporal variability of precipitation over the Southern Ocean can be-tentatively-assessed against satellite-gauge precipitation analyses. In addition, inhomogeneities in the time series related to the assimilation of satellite observations are expected to show up more clearly over the ocean than over Antarctica owing to the paramount role of satellite observations over ocean areas. Conclusions about the realism of the changes in Antarctic $P-E$ can then be inferred from the performance of the reanalyses over the Southern Ocean.

\section{a. Time series of Southern Ocean precipitation}

Figure 7 shows the time series of mean annual precipitation spatially averaged over four domains. Precipitation equatorward of $60^{\circ} \mathrm{S}$ (Fig. 7a) largely reflects the global mean. The precipitation estimates from the reanalyses-with the exception of MERRA prior to 1998 - systematically exceed those from GPCP and CMAP because of overestimated tropical rainfall in the reanalyses (Bosilovich et al. 2008). The origin of the global precipitation increase in NCEP-2 during the first part of the 1990s is still unclear. The erratic behavior of ERA-40 results from deficiencies in the moisture analysis, particularly following the eruption of Mt. Pinatubo in 1991 (Andersson et al. 2005; Uppala et al. 2005). In ERAInterim, artificial reductions in global precipitation have been linked to increases in the volume of rain-affected $\mathrm{SSM} / \mathrm{I}$ radiances used for data assimilation (Uppala et al. 2008 and D. Dee, ECMWF, 2010, personal communication). This sensitivity would explain the drop in precipitation in 1992 and its increase after 2005. As already seen over Antarctica in MERRA, the impact of AMSU is visible in global precipitation in MERRA, JRA-25, and CFSR (Onogi et al. 2007; Sakamoto and Christy 2009; Saha et al. 2010; Cullather and Bosilovich 2011). Further assessment of the global hydrological cycle in recent global reanalyses is given by Trenberth et al. (2011).

In the $50^{\circ}-60^{\circ} \mathrm{S}$ latitude band (Fig. $7 \mathrm{~b}$ ), GPCP precipitation estimates are approximately $0.9 \mathrm{~mm} \mathrm{day}^{-1}$ $(\sim 40 \%)$ higher than CMAP estimates. The reanalysis values (except for CFSR) lie between these lower and upper bounds. The large discrepancy between GPCP and CMAP is related to the use of TOVS precipitation retrievals in GPCP, but not in CMAP (Adler et al. 2003; Yin et al. 2004). The drop in JRA-25 precipitation from 1987 to 1988 coincides with the assimilation of SSM/I 
a) $60^{\circ} \mathrm{N}-60^{\circ} \mathrm{S}$

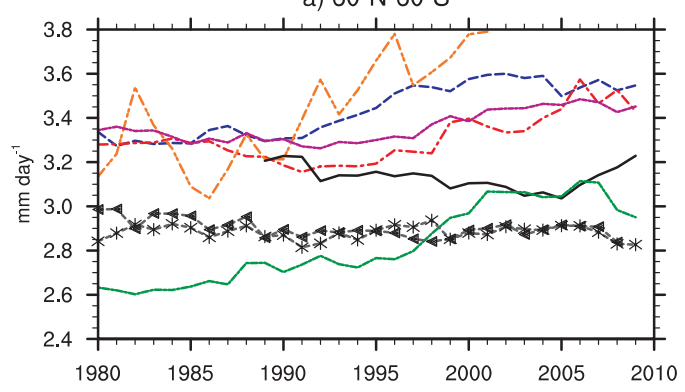

c) Ocean poleward of $60^{\circ} \mathrm{S}$

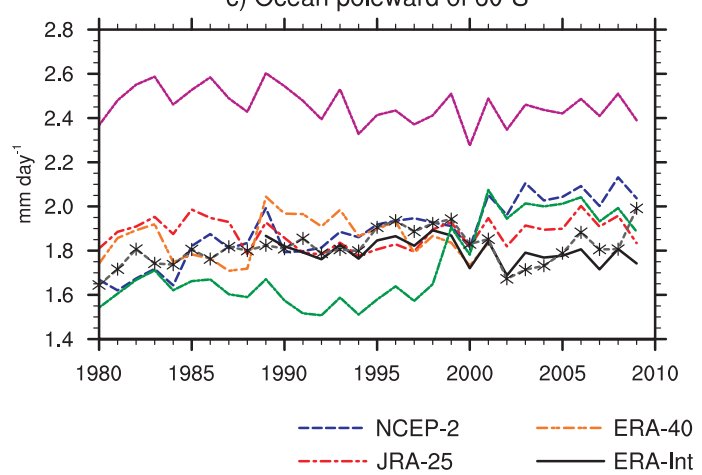

b) $50^{\circ} \mathrm{S}-60^{\circ} \mathrm{S}$

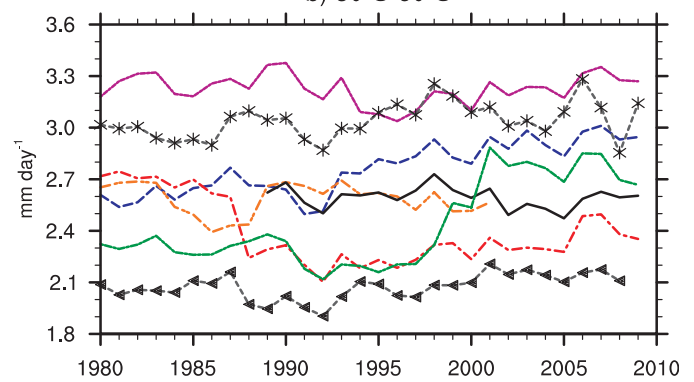

d) Antarctic continent

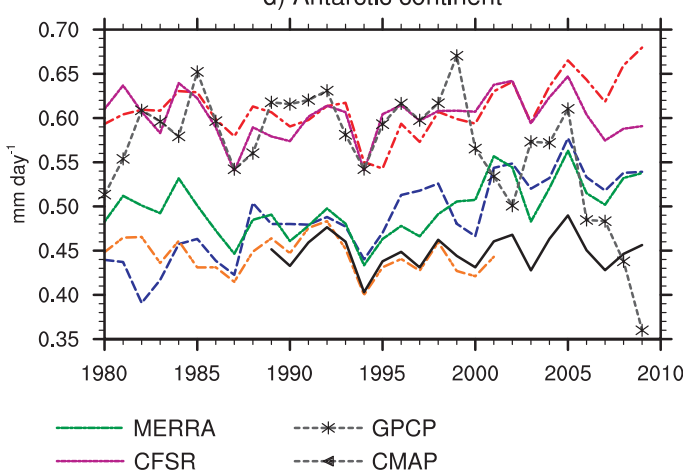

FIG. 7. Mean annual precipitation $\left(\mathrm{mm} \mathrm{day}^{-1}\right.$ ) spatially averaged over four domains: (a) $60^{\circ} \mathrm{N}-60^{\circ} \mathrm{S}$; (b) $50^{\circ}-60^{\circ} \mathrm{S}$; (c) Southern Ocean poleward of $60^{\circ} \mathrm{S}$; and (d) Antarctic continent including the floating ice shelves. The data are shown for the six reanalyses as well as for the GPCP and CMAP datasets. Owing to missing data in high latitudes, CMAP data are not shown poleward of $60^{\circ} \mathrm{S}$.

precipitable water observations (Bosilovich et al. 2006; Onogi et al. 2007).

Over the ocean poleward of $50^{\circ} \mathrm{S}$ (Figs. $7 \mathrm{~b}$ and $7 \mathrm{c}$ ), a jump in MERRA precipitation occurs between 1998 and 2001 , resulting in a $22 \%-24 \%$ increase in the annual mean, an artifact related to the introduction of AMSU radiances. Cullather and Bosilovich (2011) report a $40 \%$ increase in $P-E$. Interestingly, these authors also show than this inhomogeneity is almost unnoticeable when $P$ $E$ is computed from the moisture flux budget method. The timing of the precipitation jump in MERRA is further examined in Fig. 8. This figure shows the daily precipitation differences between MERRA and ERAInterim over the $50^{\circ}-60^{\circ} \mathrm{S}$ band. The jump actually consists of two successive steps, respectively, in late 1998 and early 2001 that are concurrent with the introduction of AMSU data from the NOAA-15 and NOAA-16 satellites.

Over the ocean south of $60^{\circ} \mathrm{S}$ (Fig. 7c), CFSR clearly stands above the other datasets, with mean annual precipitation about $0.4 \mathrm{~mm}$ day $^{-1}(\sim 25 \%)$ larger. Relatively good agreement is found between NCEP-2, JRA-25, ERA-Interim, and GPCP during the 1990s. However, the curves show contrasting evolutions from 2001 onward, with a marked upward shift in NCEP-2 (in line with
MERRA), a moderate increase in JRA-25, and a decline in ERA-Interim and GPCP.

The comments made previously about Antarctic precipitation (Fig. 4a) largely apply to Fig. 7d, which is shown here with different units and the absence of a reference year to allow for consistent comparison with lower-latitude precipitation. A striking feature in Fig. $7 \mathrm{~d}$ is the sudden

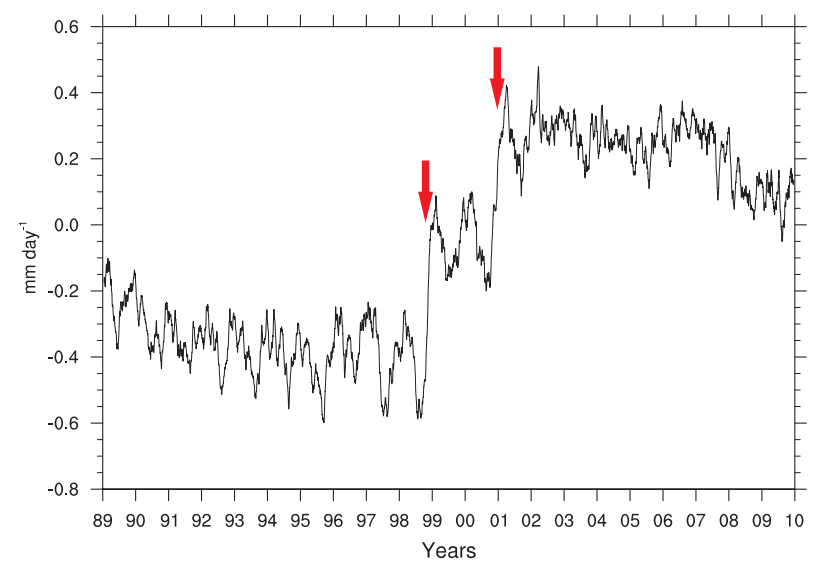

FIG. 8. Daily precipitation difference $\left(\mathrm{mm} \mathrm{day}^{-1}\right)$ between MERRA and ERA-Interim spatially averaged over the Southern Ocean between $50^{\circ}-60^{\circ} \mathrm{S}$ and smoothed with a 31-day running average. 
drop in GPCP precipitation after 1999 and continuing throughout the 2000s, making this dataset unreliable over Antarctica during this period. This sharp decrease may be caused by a reduced amount of TOVS data used in GPCP precipitation analysis from 1999 onward (Adler et al. 2003).

\section{b. Spatial distribution of precipitation trends over the Southern Hemisphere}

Figure 9 shows the 1989-2009 linear trends in precipitation over the entire Southern Hemisphere. MERRA stands out with a pattern of large positive and highly significant trends over the Southern Ocean south of $40^{\circ} \mathrm{S}$, an area in which the reanalyses are almost exclusively reliant on satellite data. Figures 4 and 5 provide strong evidence that these inhomogeneities contaminated the trends in $P-E$ over Antarctica in MERRA. Large positive trends are also found in the Pacific sector of the Southern Ocean in NCEP-2. In ERA-Interim and CFSR, small and insignificant trends prevail over the Southern Ocean. These latter two datasets differ, however, in the southwest Atlantic sector and over lower-latitude ocean areas, with widespread positive and highly significant trends in CFSR, whereas ERA-Interim generally exhibits small values.

Some overall agreement is found between GPCP and CMAP (Figs. 9e and 9f), despite the low temporal correlations between the two datasets noted by Yin et al. (2004). The precipitation trends in ERA-Interim are those that best agree with the trends from GPCP and CMAP in low and midlatitudes, although ERA-Interim exhibits more negative and significant values over the South Atlantic and southeast Pacific Oceans. Despite strong dissimilarities, the seven maps from Fig. 9 also share some common features: downward precipitation trends in the western equatorial Pacific; upward (and generally significant) trends over the South Pacific Convergence Zone (SPCZ); and southeastnorthwest contrast over Australia.

Table 4 summarizes the trends in average precipitation over the Southern Ocean (south of $50^{\circ} \mathrm{S}$ ) from the different datasets, including an ECMWF composite constructed as described in section $4 \mathrm{~b}$. The trends from the reanalyses bear much similarity with those for the Antarctic $P-E$ (Table 3), with the notable exception of JRA-25, as a result of the SSM/I-related drop in precipitation in 1987 (Fig. 7b). Highly significant (CL > 99\%) positive trends are found in NCEP-2, MERRA, and CMAP. With a positive trend significant at the 90\% CL for 1979-2009 but no significant trend for 1989-2009, GPCP behaves similarly to the combined ECMWF-ERA-Interim dataset. Trends are not significantly different from zero in CFSR for either period.

\section{Changes in the atmospheric circulation}

In this section, we investigate the contribution of the atmospheric circulation to the trends in Antarctic $P-E$ simulated by the reanalyses. Because of the large contrast in moisture content between the polar continental atmosphere and the surrounding maritime air masses (Tietäväinen and Vihma 2008), changes (real or spurious) in the meridional wind component can greatly affect the moisture transport and the associated precipitation (e.g., Schlosser et al. 2010).

\section{a. Spatial trends in $Z_{500}$ and surface pressure}

The 1989-2009 linear trends in 500-hPa geopotentional height $\left(Z_{500}\right)$ and surface pressure poleward of $50^{\circ} \mathrm{S}$ are displayed respectively in Figs. 10 and 11. A common characteristic among the reanalyses is a pattern of negative trends in the South Pacific sector of the Southern Ocean $\left(90^{\circ} \mathrm{W}-180^{\circ}\right)$. Again, the contours and magnitude of the pattern vary greatly among the five datasets. Over Antarctica, NCEP-2 and JRA-25 exhibit the largest absolute trend magnitudes but mostly with opposite signs. CFSR shows two patterns of large positive trends in $Z_{500}$ and surface pressure centered respectively over the East Antarctic plateau and over central Wilkes Land coast. In ERA-Interim, the negative pattern over the South Pacific Ocean extends over the Ross Sea and Ross Ice Shelf and across West Antarctica to Dronning Maud Land. Similar patterns are discernible in MERRA, yet, with more complex contours.

\section{b. Time series of mean $Z_{500}$ in high southern latitudes}

Tentative explanations of the discrepancies between the datasets are provided by Figs. 12 and 13. Figure 12 shows spatially averaged differences in $Z_{500}$ between the reanalyses and ERA-Interim. Over Antarctica (Fig. 12a), the $Z_{500}$ discrepancy between NCEP-2 and ERA-Interim (and the other reanalyses) becomes substantially reduced from 1998 onward. This discontinuity may originate from the transition between the assimilation of TOVS retrievals to the direct assimilation of TOVS radiances, which was to be implemented in 1998 in the NCEP-National Center for Atmospheric Research (NCAR) reanalysis (Kalnay et al. 1996) and thus, supposedly, in NCEP-2.

For JRA-25, the $Z_{500}$ difference exhibits a marked downward trend both over Antarctica (Fig. 12b) and the surrounding ocean (Fig. 12c) beginning around 1998-99. This decline may be related to the transition from TOVS to ATOVS in October 1998, which also coincided with a change in the bias correction technique applied to these sounding radiances (Onogi et al. 2007; Sakamoto and Christy 2009). For CFSR, Fig. 12 b reveals a marked positive trend in the $Z_{500}$ difference over the continent. Comparison 
a) NCEP-2

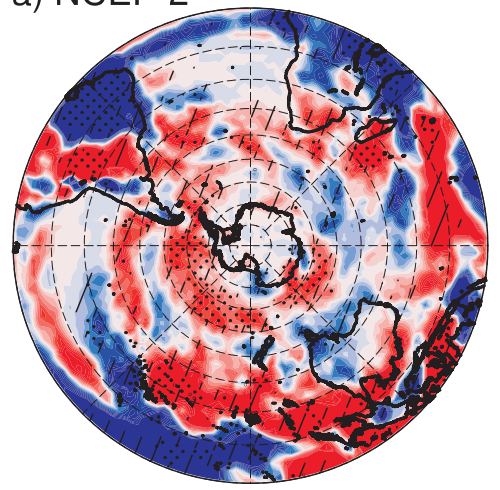

c) ERA-Int

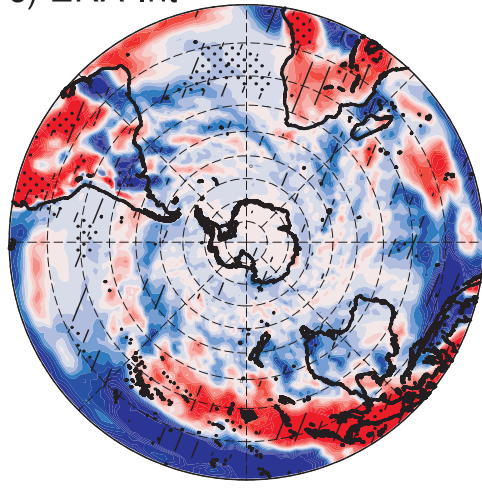

e) CFSR

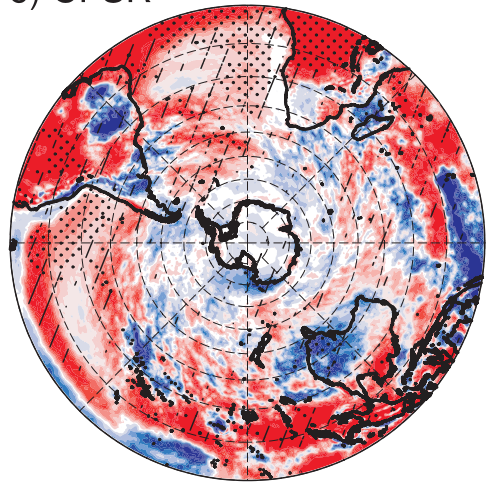

g) CMAP

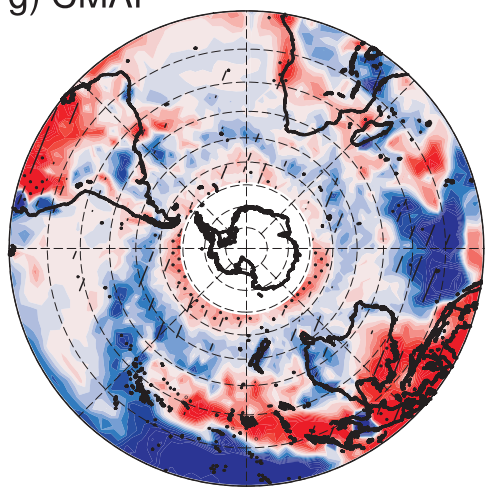

b) JRA

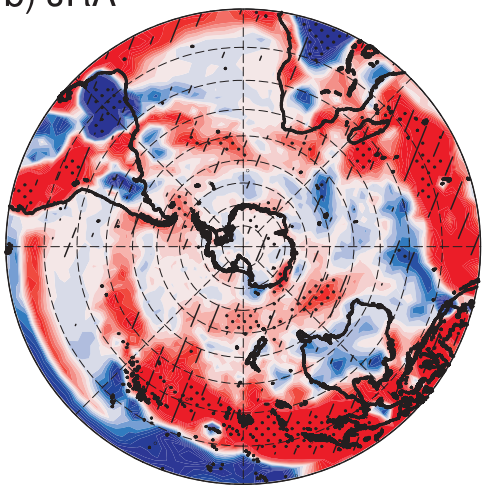

d) MERRA

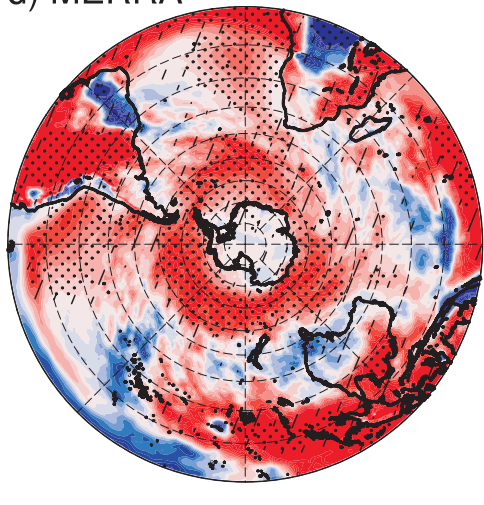

f) GPCP

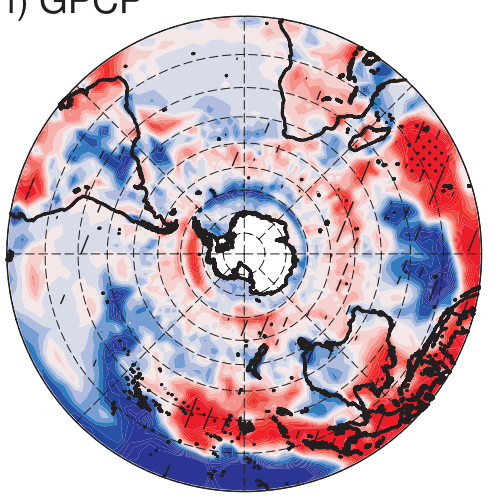

250

200

150

100

50

0

$-50$

$-100$

$-150$

$-200$

$-250$

FIG. 9. 1989-2009 linear trends in annual precipitation $\left(\mathrm{mm} \mathrm{yr}^{-1}\right.$ decade $^{-1}$ ) over the Southern Hemisphere from (a) NCEP-2, (b) JRA-25, (c) ERA-Interim, (d) MERRA, (e) CFSR, (f) GPCP, and (g) CMAP. For GPCP and CMAP, the trends are calculated only for 1989-2008. Trends over Antarctica in GPCP and poleward of $60^{\circ} \mathrm{S}$ in CMAP are masked out. Hatched (dotted) areas denote trends that are statistically different from zero at the $90 \%$ (99\%) confidence level. 
TABLE 4. As in Table 3, but for the trends in precipitation $\left(\mathrm{mm} \mathrm{day}{ }^{-1}\right.$ decade $^{-1}$ ) over the Southern Ocean (south of $50^{\circ} \mathrm{S}$ ). For GPCP and CMAP, the trends are relative to 1979-2008 and 1989-2008, respectively.

\begin{tabular}{lrr}
\hline \multicolumn{1}{c}{ Analysis } & $1979-2009$ & $1989-2009$ \\
\hline NCEP-2 & $\mathbf{0 . 1 3} \pm \mathbf{0 . 0 1}$ & $\mathbf{0 . 1 7} \pm \mathbf{0 . 0 2}$ \\
JRA-25 & $-\mathbf{0 . 0 8} \pm \mathbf{0 . 0 2}$ & $\mathbf{0 . 0 8} \pm \mathbf{0 . 0 2}$ \\
ERA- Interim & - & $-0.03 \pm 0.02$ \\
MERRA & $\mathbf{0 . 1 8} \pm \mathbf{0 . 0 3}$ & $\mathbf{0 . 3 3} \pm \mathbf{0 . 0 5}$ \\
CFSR & $-0.01 \pm 0.02$ & $0.00 \pm 0.03$ \\
ECMWF & $0.03 \pm 0.02$ & - \\
GPCP & $0.04 \pm 0.02$ & $0.02 \pm 0.03$ \\
CMAP & $\mathbf{0 . 0 4} \pm \mathbf{0 . 0 1}$ & $\mathbf{0 . 0 8} \pm \mathbf{0 . 0 2}$ \\
\hline
\end{tabular}

with radiosonde observations from Amundsen-Scott South Pole Station (not shown) indicates an upward shift in $Z_{500}$ between 1995 and 2000. Until 1996, CFSR underestimates $Z_{500}$ by $\sim 20 \mathrm{gpm}$ whereas, after 2000 , this bias is considerably reduced and comparable to the values seen in the other datasets.

\section{c. Comparison with observations from Casey}

The marked downward trends in $Z_{500}$ and surface pressure in NCEP-2 and JRA- 25 around $120^{\circ} \mathrm{E}$ contrast drastically with the upward trends in the three other reanalyses (Figs. 10 and 11). The greatest discrepancy is seen over the coast in the vicinity of the Australian Station Casey, whose mean sea level pressure (MSLP) and $Z_{500}$ observations are compared with the reanalysis data in Fig. 13.

A prominent feature in Fig. 13 is a drop in MSLP bias in NCEP-2 between 1991 and 1994. Some similarity is seen in the evolution of the $Z_{500}$ bias, although the bias becomes negative during 1994-96. Marshall (2002) showed that a sudden decrease in monthly mean $Z_{500}$ values in 1993 in the NCEP-NCAR reanalysis coincides with the assimilation of pressure observations from automatic weather stations with erroneous model heights. We speculate that the early 1990s drop (also seen in JRA-25) is linked to the end of the radiosonde program at Vostok (south of Casey) in early 1992.

In JRA-25, the large negative trends in surface pressure over Casey and the adjacent ocean sector (Fig. 11) result from decreasing pressure values in the early 1990s and after the year 2000 (Fig. 13). As mentioned in section $6 \mathrm{~b}$, the transition to ATOVS is one possible explanation for the post-2000 evolution in JRA-25 pressure/geopotential height fields.

\section{d. Conclusions from the apparent changes in the atmospheric circulation}

Overall, a clear correspondence can be established between the trends in $Z_{500}$ and surface pressure (especially the high-gradient zones) and the trends in $P-E$ from Fig. 5. In NCEP-2 and JRA-25, the changes in $Z_{500}$ and surface pressure act to greatly enhance the poleward wind flow over coastal central Wilkes Land, particularly in the vicinity of Banzare Coast $\left(128^{\circ} \mathrm{E}\right)$, where the two datasets exhibit the largest trends in $P-E$ (Fig. 6). In CFSR, the large positive trends in $Z_{500}$ and surface pressure over the East Antarctic interior and over the coast near $130^{\circ} \mathrm{E}$ account for enhanced positive and negative trends in $P-E$ in the $45^{\circ}-160^{\circ} \mathrm{E}$ sector, as compared to ERAInterim (Figs. 5c and 5e). There is, however, no apparent net impact on the Antarctic $P-E$ simulated by CFSR. A similar reasoning can be applied to other Antarctic regions such as Dronning Maud Land or West Antarctica. From the spurious origin of the trends in NCEP-2 and JRA-25, we conclude that the trends in $P-E$ in these datasets are also spurious or overestimated.

\section{Summary and implications}

This study contrasts and evaluates five global reanalyses (NCEP-2, JRA-25, ERA-Interim, MERRA, and CFSR) in the Southern Hemisphere, with a focus on changes in Antarctic $P-E$ and Southern Ocean precipitation during the 1989-2009 period. The spatial distributions of mean annual $P-E$ over Antarctica are compared with a long-term accumulation map based on in situ measurements. Excessively low $P-E$ values are found in NCEP-2 over East Antarctica. JRA-25 substantially overestimates the accumulation over the East Antarctic plateau, whereas ERA-Interim exhibits a pronounced dry bias in this area. Because of the incomplete representation of the SMB through $P-E$, the apparent agreement of MERRA and CFSR with the accumulation map indicates insufficient $P-E$ values.

The five reanalyses reveal contrasting time series and trends in annual Antarctic $P-E$ and Southern Ocean precipitation. Highly significant positive trends are found in NCEP-2, JRA-25, and MERRA during 1989-2009, whereas the trends in ERA-Interim and CFSR are not significantly different from zero. Over the Southern Ocean, the absence of significant changes is in agreement with the GPCP precipitation analyses. A jump in precipitation occurs in MERRA between 1998 and 2002 over the entire Southern Ocean, which coincides with the assimilation of AMSU radiances. Large positive trends in $P-E$ in NCEP-2 and JRA-25 are, to a significant extent, attributed to an unrealistic increase in precipitation over Wilkes Land produced by artificial trends in the pressure/ geopotential fields. A suspicious upward shift in $Z_{500}$ over East Antarctica is also found in CFSR, yet with no clear impact on the overall trend in Antarctic $P-E$, but casts doubts on the reliability of this dataset over Antarctica. 

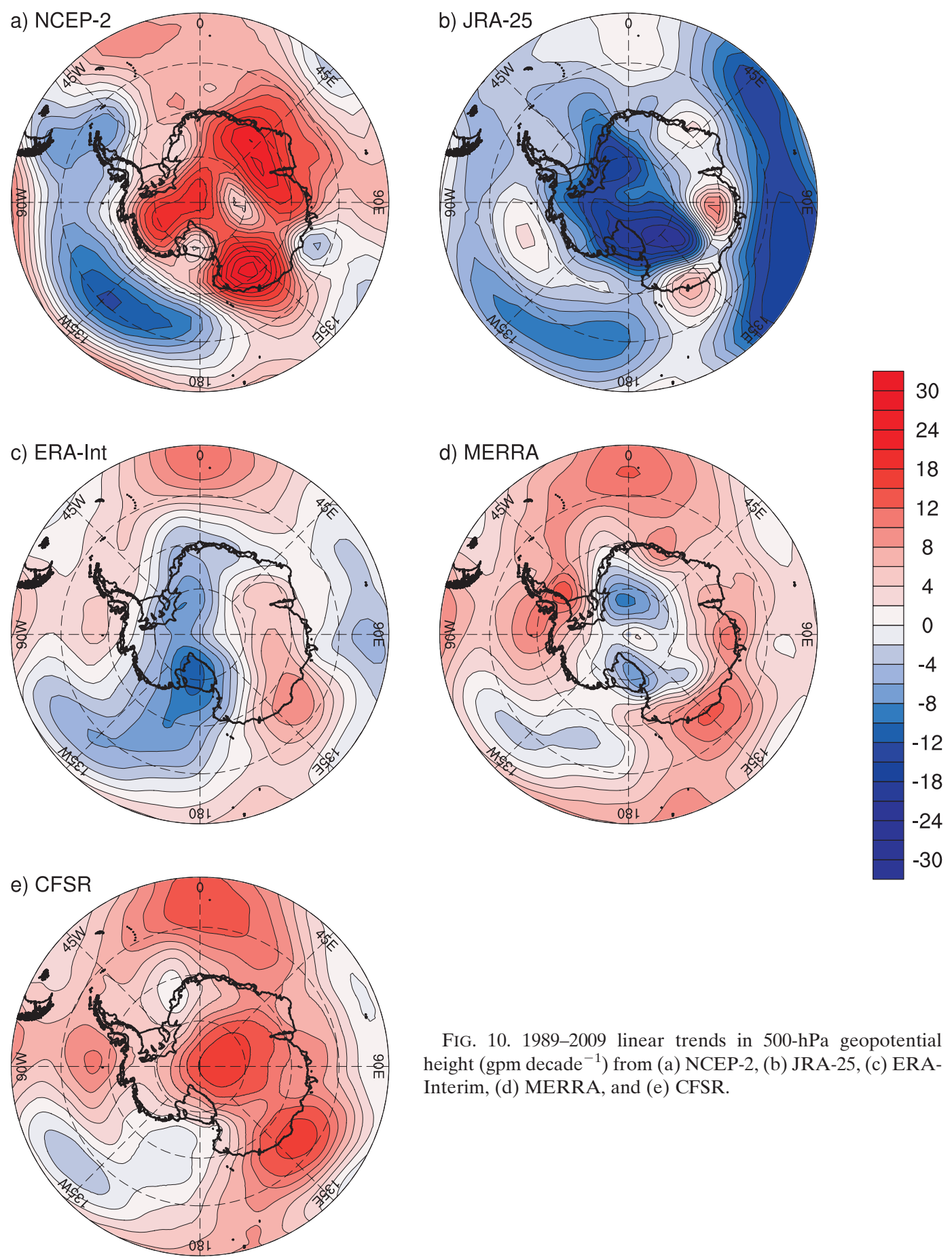

FIG. 10. 1989-2009 linear trends in 500-hPa geopotential height (gpm decade ${ }^{-1}$ ) from (a) NCEP-2, (b) JRA-25, (c) ERAInterim, (d) MERRA, and (e) CFSR.

ERA-Interim does not reveal any apparent suspicious trends or discontinuities in the high southern latitudes. However, it is not certain to what extent the negative impact of SSM/I on ERA-Interim global precipitation has affected (if at all) precipitation trends in high southern latitudes.
We conclude that ERA-Interim likely provides the most realistic depiction of the interannual variability and trends in Antarctic $P-E$ during 1989-2009. The excessively dry Antarctic interior in ERA-Interim remains a matter of concern, especially given the projected marked increase in precipitation in this area in the twenty-first 

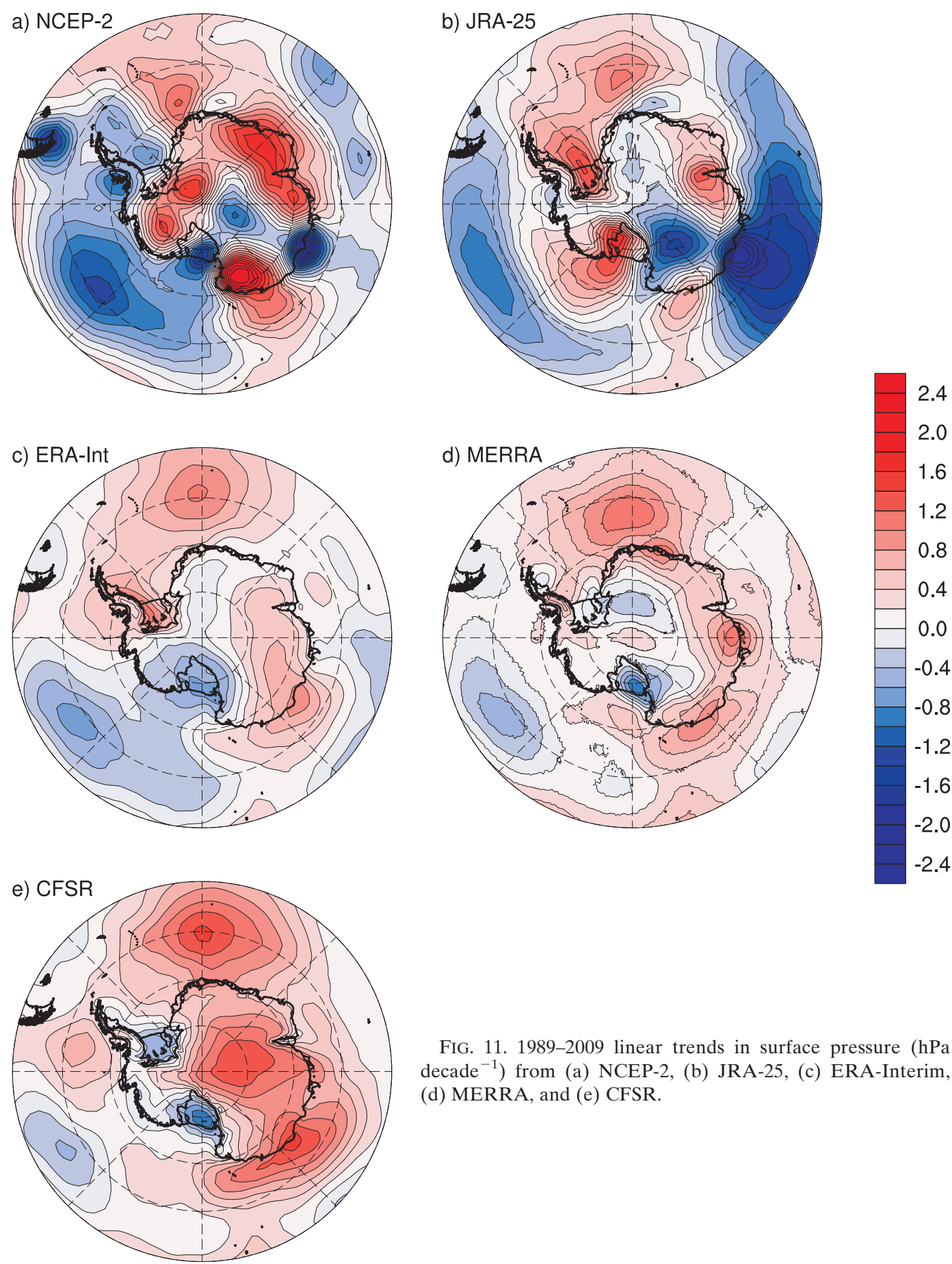

FIG. 11. 1989-2009 linear trends in surface pressure (hPa decade $^{-1}$ ) from (a) NCEP-2, (b) JRA-25, (c) ERA-Interim, (d) MERRA, and (e) CFSR.

century (Christensen et al. 2007). By not properly capturing the accumulation in this area, ERA-Interim may underestimate the overall trend in Antarctic $P-E$.

Our study shows that the large positive trends in Antarctic $P-E$ during 1989-2009 in NCEP-2, JRA-25, and MERRA are exaggerated and that nonsignificant trends, as found in ERA-Interim and CFSR, are likely closer to the "truth." This conclusion corroborates the absence of significant change in Antarctic $P-E$ previously reported by van de Berg et al. (2005), Monaghan et al. (2006a), and Monaghan et al. (2006b). The large interannual variability and the short time period investigated here mainly account for the lack of statistical significance in the linear trends and emphasize the need for longer time series. 

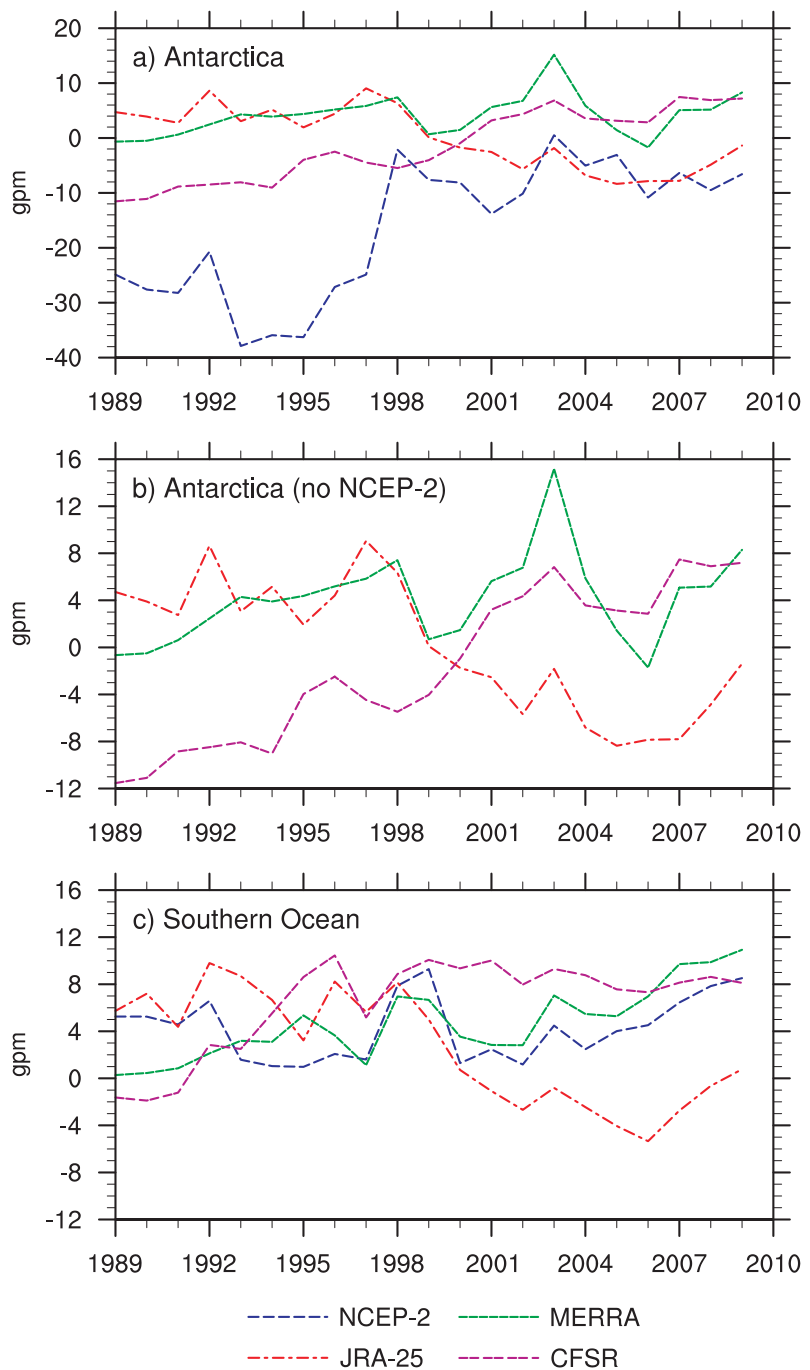

FIG. 12. Annual mean 500-hPa geopotential height difference $(\mathrm{gpm})$ with respect to ERA-Interim, spatially averaged over (a),(b) the Antarctic continent and (c) the Southern Ocean poleward of $50^{\circ} \mathrm{S}$. Note (a) and (b) are identical except that (b) does not include the NCEP-2 time series and has a vertical scale different from (a).

The "shock" represented by the dramatic increase in the volume of satellite observations in the 1990s-2000s (Dee et al. 2009; Saha et al. 2010) has proved of a different nature from what we initially conjectured. The increase in the volume of observational data results to a large extent from the new data provided by high-resolution atmospheric sounders launched in the 2000s, such as the Atmospheric Infrared Sounder (AIRS). No disruption in the reanalysis time series has been found to be associated with the introduction of these sounding radiances. Surprisingly, the assimilation of AMSU observations, with comparably few channels, appears to have a much greater impact on some of the reanalyses.
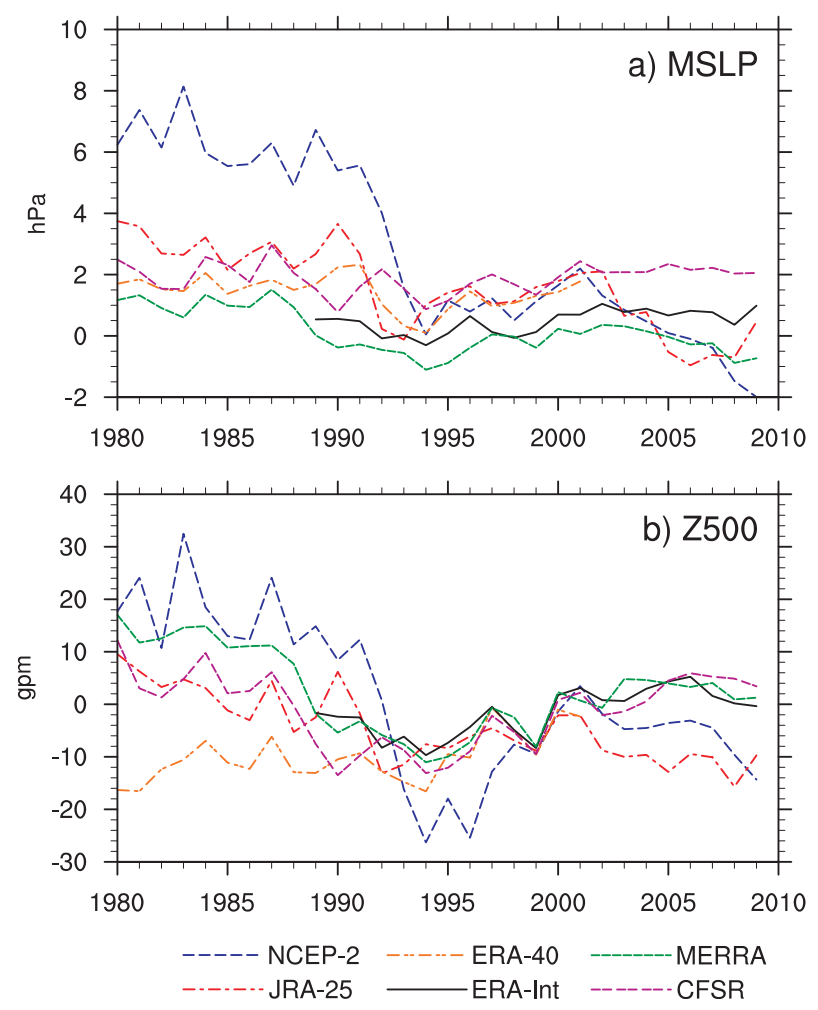

FIG. 13. Difference between reanalysis and observed values at Casey Station for (a) mean annual mean sea level pressure (hPa) and (b) mean annual 500-hPa geopotential height (gpm).

The high southern latitudes remain a challenging place for retrospective analysis experiments. The issue of artificial trends and jumps warrants caution when using these datasets for climate change assessment. The range of Antarctic $P-E$ trends among the five datasets analyzed here-between +1 and $+26 \mathrm{~mm}$ of change over the past two decades-is a difference equivalent to $1 \mathrm{~mm}$ of sea level. This discrepancy underscores the importance of improving the reanalyses simulations of Antarctic snowfall so that the contribution of the Antarctic Ice Sheet to sea level rise can better understood.

Acknowledgments. This research was funded in part by UCAR Subcontract 20020793 and NSF Grant ANT0636523. The authors thank Eric Rignot for preliminary discussions, Michael Bosilovich for information regarding MERRA, Dick Dee for information about ERAInterim, Richard Cullather and Kevin Trenberth for kindly providing their respective submitted manuscripts, and Sheng-Hung Wang for his valuable help with the data processing. The authors are also grateful to the three anonymous reviewers whose comments improved the initial manuscript. 


\section{REFERENCES}

Adler, R., and Coauthors, 2003: The version-2 global precipitation climatology project (GPCP) monthly precipitation analysis (1979-present). J. Hydrometeor., 4, 1147-1167.

Allison, I., R. Alley, H. Fricker, R. Thomas, and R. Warner, 2009: Ice sheet mass balance and sea level. Antarct. Sci., 21, 413-426.

Andersson, E., 2007: Data assimilation in the polar regions. ECMWF Newsletter, No. 112, ECMWF, Reading, United Kingdom, 10-15.

_- and Coauthors, 2005: Assimilation and modeling of the atmospheric hydrological cycle in the ECMWF forecasting system. Bull. Amer. Meteor. Soc., 86, 387-402.

—_, and Coauthors, 2007: Analysis and forecast impact of the main humidity observing systems. Quart. J. Roy. Meteor. Soc., 133, 1473-1485.

Anschütz, H., O. Eisen, H. Oerter, D. Steinhage, and M. Scheinert, 2007: Investigating small-scale variations of the recent accumulation rate in coastal Dronning Maud Land, East Antarctica. Ann. Glaciol., 46, 14-21.

—, K. Müller, E. Isaksson, J. R. McConnell, H. Fischer, H. Miller, M. Albert, and J.-G. Winther, 2009: Revisiting sites of the South Pole Queen Maud Land traverses in East Antarctica: Accumulation data from shallow firn cores. J. Geophys. Res., 114, D24106, doi:10.1029/2009JD012204.

Arthern, R. J., D. P. Winebrenner, and D. G. Vaughan, 2006: Antarctic snow accumulation mapped using polarization of 4.3-cm wavelength microwave emission. J. Geophys. Res., 111, D06107, doi:10.1029/2004JD005667.

Bengtsson, L., and J. Shukla, 1988: Integration of space and in situ observations to study global climate change. Bull. Amer. Meteor. Soc., 69, 1130-1143.

_ S. Hagemann, and K. I. Hodges, 2004a: Can climate trends be calculated from reanalysis data? J. Geophys. Res., 109, D11111, doi:10.1029/2004JD004536.

_ K. K. I. Hodges, and S. Hagemann, 2004b: Sensitivity of the ERA40 reanalysis to the observing system: Determination of the global atmospheric circulation from reduced observations. Tellus, 56A, 456-471.

— analysis. Bull. Amer. Meteor. Soc., 88, 495-501.

Bintanja, R., 1998: The contribution of snowdrift sublimation to the surface mass balance of Antarctica. Ann. Glaciol., 27, 251-259.

Bosilovich, M. G., and Coauthors, 2006: NASA's modern era retrospective-analysis for research and applications. U.S CLIVAR Variations, No. 4, International CLIVAR Project Office, Southampton, United Kingdom, 5-8. [Available online at http://www.usclivar.org/Newsletter/VariationsV4N2.pdf.]

— J. Chen, F. R. Robertson, and R. F. Adler, 2008: Evaluation of precipitation in reanalyses. J. Appl. Meteor. Climatol., 47, 2279-2299.

Bouchard, A., F. Rabier, V. Guidard, and F. Karbou, 2010: Enhancements of satellite data assimilation over Antarctica. Mon. Wea. Rev., 138, 2149-2173.

Bromwich, D. H., 1988: Snowfall in high southern latitudes. Rev. Geophys., 26, 149-168.

- and R. L. Fogt, 2004: Strong trends in the skill of the ERA-40 and NCEP-NCAR reanalyses in the high and middle latitudes of the Southern Hemisphere, 1958-2001. J. Climate, 17, 46034619.
— , and S.-H. Wang, 2008: A review of the temporal and spatial variability of Arctic and Antarctic atmospheric circulations based upon ERA-40. Dyn. Atmos. Oceans, 44, 213-243.

- R. L. Fogt, K. I. Hodges, and J. E. Walsh, 2007: A tropospheric assessment of the ERA-40, NCEP, and JRA-25 global reanalyses in the polar regions. J. Geophys. Res., 112, D10111, doi:10.1029/2006JD007859.

Christensen, J. H., and Coauthors, 2007: Regional climate projections. Climate Change 2007: The Physical Science Basis, S. Solomon et al., Eds., Cambridge University Press, 847-940.

Church, J. A., J. Gregory, P. Huybrechts, M. Kuhn, K. Lambeck, M. Nhuan, D. Qin, and P. Woodworth, 2001: Changes in sea level. Climate Change 2001: The Scientific Basis, J. Houghton et al., Eds., Cambridge University Press, 639-693.

Cucurull, L., Y. H. Kuo, D. Barker, and S. R. H. Rizvi, 2006: Assessing the impact of simulated COSMIC GPS radio occultation data on weather analysis over the Antarctic: A case study. Mon. Wea. Rev., 134, 3283-3296.

Cullather, R. I., and M. G. Bosilovich, 2011: The moisture budget of the polar atmosphere in MERRA. J. Climate, 24, 28612879.

Dee, D., and S. Uppala, 2008: Variational bias correction in ERAInterim. ECMWF Tech. Memo. 575, 28 pp.

, and - 2009: Variational bias correction of satellite radiance data in the ERA-Interim reanalysis. Quart. J. Roy. Meteor. Soc., 135, 1830-1841.

, P. Berrisford, P. Poli, and M. Fuentes, 2009: ERA-Interim for climate monitoring. ECMWF Newsletter, No. 119, ECMWF, Reading, United Kingdom, 5-6. [Available online at http:// www.ecmwf.int/publications/newsletters/pdf/119.pdf.]

Déry, S. J., and M. K. Yau, 2002: Large-scale mass balance effects of blowing snow and surface sublimation. J. Geophys. Res., 107, 4679, doi:10.1029/2001JD001251.

Fernandoy, F., H. Meyer, H. Oerter, F. Wilhelms, W. Graf, and J. Schwander, 2010: Temporal and spatial variation of stableisotope ratios and accumulation rates in the hinterland of Neumayer station, East Antarctica. J. Glaciol., 56, 673-687.

Frezzotti, M., and Coauthors, 2004: New estimations of precipitation and surface sublimation in East Antarctica from snow accumulation measurements. Climate Dyn., 23, 803-813.

, S. Urbini, M. Proposito, C. Scarchilli, and S. Gandolfi, 2007: Spatial and temporal variability of surface mass balance near Talos Dome, East Antarctica. J. Geophys. Res., 112, F02032, doi:10.1029/2006JF000638.

Fujita, K., and O. Abe, 2006: Stable isotopes in daily precipitation at Dome Fuji, East Antarctica. Geophys. Res. Lett., 33, L18503, doi:10.1029/2006GL026936.

Genthon, C., P. Lardeux, and G. Krinner, 2007: The surface accumulation and ablation of a coastal blue-ice area near Cap Prudhomme, Terre Adelie, Antarctica. J. Glaciol., 53, 635-645.

— - O. Magand, G. Krinner, and M. Fily, 2009: Do climate models underestimate snow accumulation on the Antarctic plateau? A re-evaluation of/from in situ observations in East Wilkes and Victoria Land. Ann. Glaciol., 50, 61-65.

Guedj, S., F. Karbou, F. Rabier, and A. Bouchard, 2010: Toward a better modelling of surface emissivity to improve AMSU data assimilation over Antarctica. IEEE Trans. Geosci. Remote Sens., 48, 1976-1985.

Haimberger, L., 2007: Homogenization of radiosonde temperature time series using innovation statistics. J. Climate, 20, 13771403. 
Healy, S., 2007: Operational assimilation of GPS radio occultation measurements at ECMWF. ECMWF Newsletter, No. 111, ECMWF, Reading, United Kingdom, 6-11.

Hines, K. M., R. W. Grumbine, D. H. Bromwich, and R. I. Cullather, 1999: Surface energy balance of the NCEP MRF and NCEP/ NCAR Reanalysis in Antarctic latitudes during FROST. Wea. Forecasting, 14, 851-866.

—, D. H. Bromwich, and G. J. Marshall, 2000: Artificial surface pressure trends in the NCEP/NCAR reanalysis over the Southern Ocean and Antarctica. J. Climate, 13, 3940-3952.

Kalnay, E., and Coauthors, 1996: The NCEP/NCAR 40-Year Reanalysis Project. Bull. Amer. Meteor. Soc., 77, 437-471.

Kameda, T., H. Motoyama, S. Fujita, and S. Takahashi, 2008: Temporal and spatial variability of surface mass balance at Dome Fuji, East Antarctica, by the stake method from 1995 to 2006. J. Glaciol., 54, 107-116.

Kanamitsu, M., W. Ebisuzaki, J. Woollen, S.-K. Yang, J. J. Hnilo, M. Fiorino, and G. L. Potter, 2002: NCEP-DOE AMIP-II Reanalysis (R-2). Bull. Amer. Meteor. Soc., 83, 1631-1643.

Kleist, D. T., D. F. Parrish, J. C. Derber, R. Treadon, W.-S. Wu, and S. Lord, 2009: Introduction of the GSI into the NCEP Global Data Assimilation System. Wea. Forecasting, 24, 16911705.

Krinner, G., O. Magand, I. Simmonds, C. Genthon, and J.-L. Dufresne, 2007: Simulated Antarctic precipitation and surface mass balance at the end of twentieth and twenty-first centuries. Climate Dyn., 28, 215-230.

Lenaerts, J. T. M., M. R. van den Broeke, S. J. Déry, G. KönigLanglo, J. Ettema, and P. K. Munneke, 2010: Modelling snowdrift sublimation on an Antarctic ice shelf. The Cryosphere, 4, 179-190.

Liston, G. E., and J.-G. Winther, 2005: Antarctic surface and subsurface snow and ice melt fluxes. J. Climate, 18, 1469-1481.

Liu, H., K. Jezek, B. Li, and Z. Zhao, cited 2001: Radarsat Antarctic Mapping Project digital elevation model version 2. [Available online at http://nsidc.org/data/nsidc-0082.html.]

Magand, O., C. Genthon, M. Fily, G. Krinner, G. Picard, M. Frezzotti, and A. Ekaykin, 2007: An up-to-date quality-controlled surface mass balance data set for the $90^{\circ}-180^{\circ} \mathrm{E}$ Antarctic sector and 1950-2005 period. J. Geophys. Res., 112, D12106, doi:10.1029/ 2007JD008700.

— , G. Picard, L. Brucker, M. Fily, and C. Genthon, 2008: Snow melting bias in microwave mapping of Antarctic snow accumulation. The Cryosphere, 2, 109-115.

Marshall, G. J., 2002: Trends in Antarctic geopotential height and temperature: A comparison between radiosonde and NCEPNCAR reanalysis data. J. Climate, 15, 659-674.

Monaghan, A. J., and D. H. Bromwich, 2008: Advances in describing recent Antarctic climate variability. Bull. Amer. Meteor. Soc., 89, 1295-1306.

$\longrightarrow, \ldots$, and S.-H. Wang, 2006a: Recent trends in Antarctic snow accumulation from Polar MM5 simulations. Philos. Trans. Roy. Soc. London, A364, 1683-1708.

— , and Coauthors, 2006b: Insignificant change in Antarctic snowfall since the International Geophysical Year. Science, 313, 827-831.

Onogi, K., and Coauthors, 2007: The JRA-25 Reanalysis. J. Meteor. Soc. Japan, 85, 369-432.

Poli, P., S. B. Healy, and D. P. Dee, 2010: Assimilation of Global Positioning System radio occultation data in the ECMWF ERA-Interim reanalysis. Quart. J. Roy. Meteor. Soc., 136, 19721990.
Pritchard, H. D., R. J. Arthern, D. G. Vaughan, and L. A. Edwards, 2009: Extensive dynamic thinning on the margins of the Greenland and Antarctic ice sheets. Nature, 461, 971-975.

Rienecker, M. M., and Coauthors, 2008: The GEOS-5 Data Assimilation System-Documentation of versions 5.0.1, 5.1.0, and 5.2.0. NASA Tech. Rep. NASA/TM-2008-104606, Vol. 27, $92 \mathrm{pp}$.

Rignot, E., J. L. Bamber, M. R. van den Broeke, C. Davis, Y. Li, W. J. van de Berg, and E. van Meijgaard, 2008: Recent Antarctic ice mass loss from radar interferometry and regional climate modelling. Nat. Geosci., 1, 106-110.

Rogers, R. R., and M. K. Yau, 1989: A Short Course in Cloud Physics. Pergamon Press, 235 pp.

Saha, S., and Coauthors, 2010: The NCEP Climate Forecast System Reanalysis. Bull. Amer. Meteor. Soc., 91, 1015-1057.

Sakamoto, M., and J. R. Christy, 2009: The influences of TOVS radiance assimilation on temperature and moisture tendencies in JRA-25 and ERA-40. J. Atmos. Oceanic Technol., 26, 1435 1455.

Scarchilli, C., M. Frezzotti, P. Grigioni, L. De Silvestri, L. Agnoletto, and S. Dolci, 2010: Extraordinary blowing snow transport events in East Antarctica. Climate Dyn., 34, 1195-1206.

Schlosser, E., K. W. Manning, J. G. Powers, M. G. Duda, G. Birnbaum, and K. Fujita, 2010: Characteristics of highprecipitation events in Dronning Maud Land, Antarctica. J. Geophys. Res., 115, D14107, doi:10.1029/2007JD008700.

Serreze, M. C., A. P. Barrett, and F. Lo, 2005: Northern highlatitude precipitation as depicted by atmospheric reanalyses and satellite retrievals. Mon. Wea. Rev., 133, 3407-3430.

Simmons, A., S. Uppala, D. Dee, and S. Kobayashi, 2006: ERAInterim: New ECMWF reanalysis products from 1989 onwards. ECMWF Newsletter, No. 110, ECMWF, Reading, United Kingdom, 25-35. [Available online at http://www.ecmwf.int/ publications/newsletters/pdf/110_rev.pdf.]

- K. M. Willett, P. D. Jones, P. W. Thorne, and D. P. Dee, 2010: Low-frequency variations in surface atmospheric humidity, temperature, and precipitation: Inferences from reanalyses and monthly gridded observational data sets. J. Geophys. Res., 115, D01110, doi:10.1029/2009JD012442.

Sodemann, H., and A. Stohl, 2009: Asymmetries in the moisture origin of Antarctic precipitation. Geophys. Res. Lett., 36, L22803, doi:10.1029/2009GL040242.

Stammerjohn, S. E., D. G. Martinson, R. C. Smith, X. Yuan, and D. Rind, 2008: Trends in Antarctic annual sea ice retreat and advance and their relation to El Niño-Southern Oscillation and Southern Annular Mode variability. J. Geophys. Res., 113, C03S90, doi:10.1029/2007JC004269.

Thomas, E. R., G. J. Marshall, and J. R. McConnell, 2008: A doubling in snow accumulation in the western Antarctic Peninsula since 1850. Geophys. Res. Lett., 35, L01706, doi:10.1029/ 2007 GL032529.

Tietäväinen, H., and T. Vihma, 2008: Atmospheric moisture budget over Antarctica and the Southern Ocean based on the ERA-40 reanalysis. Int. J. Climatol., 28, 1977-1995.

Trenberth, K. E., J. T. Fasullo, and J. Mackaro, 2011: Atmospheric moisture transports from ocean to land and global energy flows in reanalyses. J. Climate, in press.

Turner, J., and Coauthors, 2009: Non-annular atmospheric circulation change induced by stratospheric ozone depletion and its role in the recent increase of Antarctic sea ice extent. Geophys. Res. Lett., 36, L08502, doi:10.1029/2009GL037524.

Uppala, S. M., and Coauthors, 2005: The ERA-40 Re-Analysis. Quart. J. Roy. Meteor. Soc., 131, 2961-3012. 
_ D. Dee, S. Kobayashi, P. Berrisford, and A. Simmons, 2008: Towards a climate data assimilation system: Status update of ERA-Interim. ECMWF Newsletter, No. 115, ECMWF, Reading, United Kingdom, 12-18. [Available online at http:// www.ecmwf.int/publications/newsletters/pdf/115_rev.pdf.] van de Berg, W. J., M. R. van den Broeke, C. H. Reijmer, and E. van Meijgaard, 2005: Characteristics of the Antarctic surface mass balance, 1958-2002, using a regional atmospheric climate model. Ann. Glaciol., 41, 97-104.

$-, \ldots, \ldots$, and — 2006: Reassessment of the Antarctic surface mass balance using calibrated output of a regional atmospheric climate model. J. Geophys. Res., 111, D11104, doi:10.1029/2005JD006495.

van den Broeke, M. R., C. H. Reijmer, and R. S. W. van de Wal, 2004: A study of the surface mass balance in Dronning Maud Land, Antarctica, using automatic weather stations. J. Glaciol., 50, 565-582.

- W. J. van de Berg, and E. van Meijgaard, 2006a: Snowfall in coastal West Antarctica much greater than previously assumed. Geophys. Res. Lett., 33, L02505, doi:10.1029/2005GL025239.

,,--- , and C. Reijmer, 2006b: Identification of Antarctic ablation areas using a regional atmospheric climate model. J. Geophys. Res., 111, D18110, doi:10.1029/2006JD007127. van Ommen, T. D., and V. Morgan, 2010: Snowfall increase in coastal East Antarctica linked with southwest Western Australian drought. Nat. Geosci., 3, 267-272.

_ - _ and M. A. Curran, 2004: Deglacial and Holocene changes in accumulation at Law Dome, East Antarctica. Ann. Glaciol., 39, 359-365.

Vasiljevic, D., E. Andersson, L. Isaksen, and A. Garcia-Mendez, 2006: Surface pressure bias correction in data assimilation. ECMWF Newsletter, No. 108, ECMWF, Reading, United Kingdom, 20-27. [Available online at http://www.ecmwf.int/ publications/newsletters/pdf/108.pdf.]

Vaughan, D. G., J. L. Bamber, M. Giovinetto, J. Russell, and A. P. R. Cooper, 1999: Reassessment of net surface mass balance in Antarctica. J. Climate, 12, 933-946.

Winther, J.-G., M. N. Jespersen, and G. E. Liston, 2001: Blue-ice areas in Antarctica derived from NOAA AVHRR satellite data. J. Glaciol., 47, 325-334.

Xie, P., and P. Arkin, 1997: Global precipitation: A 17-year monthly analysis based on gauge observations, satellite estimates, and numerical model outputs. Bull. Amer. Meteor. Soc., 78, 2539-2558.

Yin, X., A. Gruber, and P. Arkin, 2004: Comparison of the GPCP and CMAP merged gauge-satellite monthly precipitation products for the period 1979-2001. J. Hydrometeor., 5, 12071222. 